\title{
The representation of solar cycle signals in stratospheric ozone - Part 1: A comparison of recently updated satellite observations
}

\author{
Amanda C. Maycock ${ }^{1,2, a}$, Katja Matthes ${ }^{3,4}$, Susann Tegtmeier ${ }^{3}$, Rémi Thiéblemont ${ }^{3}$, and Lon Hood ${ }^{5}$ \\ ${ }^{1}$ Centre for Atmospheric Science, University of Cambridge, Cambridge, UK \\ ${ }^{2}$ National Centre for Atmospheric Science, University of Cambridge, Cambridge, UK \\ ${ }^{3}$ GEOMAR Helmholtz for Ocean Research, Kiel, Germany \\ ${ }^{4}$ Christian-Albrechts Universität zu Kiel, Kiel, Germany \\ ${ }^{5}$ Lunar and Planetary Laboratory, University of Arizona, Tucson, Arizona, USA

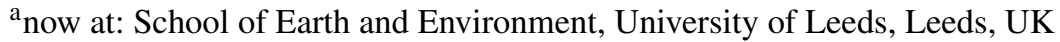 \\ Correspondence to: Amanda C. Maycock (a.c.maycock@leeds.ac.uk)
}

Received: 27 October 2015 - Published in Atmos. Chem. Phys. Discuss.: 15 January 2016

Revised: 24 June 2016 - Accepted: 7 July 2016 - Published: 9 August 2016

\begin{abstract}
Changes in incoming solar ultraviolet radiation over the 11-year solar cycle affect stratospheric ozone abundances. It is important to quantify the magnitude, structure, and seasonality of the associated solar-ozone response (SOR) to understand the impact of the 11-year solar cycle on climate. Part 1 of this two-part study uses multiple linear regression analysis to extract the SOR in a number of recently updated satellite ozone datasets covering different periods within the epoch 1970 to 2013. The annual mean SOR in the updated version 7.0 (v7.0) Stratospheric Aerosol and Gas Experiment (SAGE) II number density dataset (1984-2004) is very consistent with that found in the previous v6.2. In contrast, we find a substantial decrease in the magnitude of the SOR in the tropical upper stratosphere in the SAGE II v7.0 mixing ratio dataset $(\sim 1 \%)$ compared to the v6.2 $(\sim 4 \%)$. This difference is shown to be largely attributable to the change in the independent stratospheric temperature dataset used to convert SAGE II ozone number densities to mixing ratios. Since these temperature records contain substantial uncertainties, we suggest that datasets based on SAGE II number densities are currently most reliable for evaluating the SOR. We further analyse three extended ozone datasets that combine SAGE II v7.0 number densities with more recent GOMOS (Global Ozone Monitoring by Occultation of Stars) or OSIRIS (Optical Spectrograph and Infrared Imager System) measurements. The extended SAGE-OSIRIS dataset (1984-2013) shows a smaller and less statistically significant SOR across much of the tropical upper strato-
\end{abstract}

sphere compared to the SAGE II data alone. In contrast, the two SAGE-GOMOS datasets (1984-2011) show SORs that are in closer agreement with the original SAGE II data and therefore appear to provide a more reliable estimate of the SOR. We also analyse the SOR in the recent Solar Backscatter Ultraviolet Instrument (SBUV) Merged Ozone Dataset (SBUVMOD) version 8.6 (VN8.6) (1970-2012) and SBUV Merged Cohesive VN8.6 (1978-2012) datasets and compare them to the previous SBUVMOD VN8.0 (1970-2009). Over their full lengths, the three records generally agree in terms of the broad magnitude and structure of the annual mean SOR. The main difference is that SBUVMOD VN8.6 shows a smaller and less significant SOR in the tropical upper stratosphere and therefore more closely resembles the SAGE II v7.0 mixing ratio data than does the SBUV Merged Cohesive VN8.6, which has a more continuous SOR of $\sim 2 \%$ in this region. The sparse spatial and temporal sampling of limb satellite instruments prohibits the extraction of sub-annual variations in the SOR from SAGE-based datasets. However, the SBUVMOD VN8.6 dataset suggests substantial monthto-month variations in the SOR, particularly in the winter extratropics, which may be important for the proposed highlatitude dynamical response to the solar cycle. Overall, the results highlight substantial uncertainties in the magnitude and structure of the observed SOR from different satellite records. The implications of these uncertainties for understanding and modelling the effects of solar variability on climate should be explored. 


\section{Introduction}

Whilst fractional changes in total solar irradiance (TSI) between the maximum and minimum phases of the approximately 11-year solar cycle are known to be small $(<0.1 \%)$, there is enhanced fractional variability in the ultraviolet (UV) spectral region (>6\%) (e.g. Ermolli et al., 2013). An increase in UV irradiance impacts stratospheric heating rates, and thus temperatures, through two main mechanisms: (1) enhanced absorption of radiation by ozone and (2) enhanced production of ozone through the photolysis of oxygen at wavelengths less than $242 \mathrm{~nm}$. Consistent with these mechanisms, past studies using observations, reanalysis data, and models have identified an increase in annual mean temperature in the upper stratosphere of up to $\sim 1.5 \mathrm{~K}$ between solar maximum and minimum (e.g. Ramaswamy et al., 2001; Mitchell et al., 2015a; Austin et al., 2008) and an increase in ozone abundances of a few percent (Soukharev and Hood, 2006; Haigh, 1994). These radiatively driven changes modify the meridional temperature gradients in the upper stratosphere, which can lead to a modulation of planetary wave propagation and breaking and changes in the strength of the stratospheric polar vortex (e.g. Kuroda and Kodera, 2002; Matthes et al., 2004, 2006; Gray et al., 2010; Ineson et al., 2011). Such feedback mechanisms can lead to amplified changes in regional surface climate via stratospheretroposphere dynamical coupling (e.g. Gray et al., 2010). Constraining the stratospheric response to solar forcing is therefore important for understanding solar-climate coupling and potential sources of decadal variability in the climate system (e.g. Thiéblemont et al., 2015).

The solar-ozone response (SOR) has been estimated to make a substantial contribution to variations in stratospheric temperatures over the 11-year solar cycle. Gray et al. (2009) used an estimate of the SOR from SAGE II (Stratospheric Aerosol and Gas Experiment II) version 6.2 (v6.2) satellite ozone mixing ratio data and spectral solar irradiance (SSI) variations from Lean (2000) to show that the contribution of the SOR to temperature changes between the maximum and minimum phases of the 11 -year solar cycle is around $60 \%$ at the tropical stratopause, $30-40 \%$ between 40 and $50 \mathrm{~km}$, and $70-80 \%$ between 20 and $30 \mathrm{~km}$. Shibata and Kodera (2005) conducted similar calculations using estimates of the SOR from two atmospheric chemical models and found that the SOR accounted for only around $20-25 \%$ of the solar cycle temperature response near the tropical stratopause. Since the two studies used similar SSI datasets, this difference must arise from the SOR estimated from SAGE II observations used by Gray et al. (2009) being different from that simulated in the atmospheric chemistry models used by Shibata and Kodera (2005). It is therefore important to evaluate the SOR and its uncertainties in different observational datasets to understand the climate response to solar variability and to provide an independent means for evaluating the perfor- mance of atmospheric chemistry models (e.g. Austin et al., 2008; see also Part 2, Maycock et al., 2016).

Whilst past studies have quantified the SOR in observations (e.g. Soukharev and Hood, 2006; Randel and Wu, 2007; Remsberg and Lingenfelser, 2010; Remsberg, 2014; Bourassa et al., 2014; Lean, 2014), there are differences in the magnitudes and structures between individual satellite records. It is not clear whether these are due to interinstrument differences in observational periods and/or differences in instrument resolution, sampling, or drifts. There are also apparent differences in the structure and magnitude of the SOR between observations and atmospheric chemistry models (e.g. Haigh, 1994; Soukharev and Hood, 2006; Austin et al., 2008; Dhomse et al., 2011). These issues are compounded by current uncertainties in the characteristics of SSI variability (e.g. Ermolli et al., 2013), which have implications for constraining the magnitude and structure of the SOR because of its dependence on photochemical processes (Haigh et al., 2010; Dhomse et al., 2016; Ball et al., 2016). These factors present an additional challenge for understanding and evaluating the overall climate response to solar variability, particularly since dynamical feedbacks may amplify the effects of an initially small forcing (e.g. Matthes et al., 2006; Ineson et al., 2015).

The aim of this two-part study (see also Maycock et al., 2016) is to evaluate the representation of the SOR and its uncertainties in satellite observations and global models. The present Part 1 describes the SOR in the latest version 7.0 (v7.0) of the SAGE II dataset and compares it to the former v6.2, which has been used in several solar-climate studies (e.g. Soukharev and Hood, 2006; Gray et al., 2009) as well as in several ozone databases developed for climate models without interactive chemistry (Cionni et al., 2011; Bodeker et al., 2013). A number of merged satellite ozone datasets, which extend SAGE II using more recent measurements, have also been created and analysed as part of the WCRP/SPARC (World Climate research Programme/Stratosphere-troposphere Processes and their Role in Climate) $\mathrm{SI}^{2} \mathrm{~N}$ ozone trends activity (e.g. Tummon et al., 2015); we analyse the SOR in three of these combined satellite ozone datasets. We also analyse the SOR in two versions of the recently released version 8.6 (VN8.6) of the Solar Backscatter Ultraviolet Instrument (SBUV) data and compare these to the former SBUV Merged Ozone Dataset (SBUVMOD) VN8.0 data.

Part 2 of the study (Maycock et al., 2016) describes the SOR in chemistry-climate model simulations from the WCRP/SPARC Chemistry-Climate Model Initiative (CCMI) and compares them to a subset of the observational records discussed here that are determined to be most reliable for diagnosing the SOR (see below). Part 2 also discusses the representation of the SOR in the climate model ozone dataset created for the fifth Coupled Model Intercomparison Project (CMIP5) (Cionni et al., 2011). This leads to a discussion of 
Table 1. Overview of the satellite ozone datasets used in this study.

\begin{tabular}{|c|c|c|c|c|}
\hline Dataset & Type & Time period & Units & Reference \\
\hline SAGE II v6.2 & $\begin{array}{l}\text { Raw satellite product: solar } \\
\text { occultation instrument }\end{array}$ & 1984-2004 & ppmv; $\mathrm{cm}^{-3}$ & Wang et al. (2002) \\
\hline SAGE II v7.0 & $\begin{array}{l}\text { Raw satellite product: solar } \\
\text { occultation instrument }\end{array}$ & 1984-2004 & ppmv; $\mathrm{cm}^{-3}$ & Damadeo et al. (2013) \\
\hline SAGE-GOMOS 1 & $\begin{array}{l}\text { Combined satellite product, } \\
\text { including SAGE II v7.0 }\end{array}$ & 1984-2011 & $\mathrm{cm}^{-3}$ & Kyrölä et al. (2013) \\
\hline SAGE-GOMOS 2 & $\begin{array}{l}\text { Combined satellite product, } \\
\text { including SAGE II v7.0 }\end{array}$ & 1984-2011 & $\mathrm{cm}^{-3}$ & Penckwitt et al. (2015) \\
\hline SAGE-OSIRIS & $\begin{array}{l}\text { Combined satellite product, } \\
\text { including SAGE II v7.0 }\end{array}$ & 1984-2013 & $\mathrm{cm}^{-3}$ & Bourassa et al. (2014) \\
\hline SBUVMOD VN8.0 & $\begin{array}{l}\text { Raw satellite product: } \\
\text { nadir-viewing instrument }\end{array}$ & 1970-2009 & ppmv & \\
\hline SBUVMOD VN8.6 & $\begin{array}{l}\text { Raw satellite product: } \\
\text { nadir-viewing instrument }\end{array}$ & 1970-2012 & ppmv & $\begin{array}{l}\text { McPeters et al. (2013); } \\
\text { Frith et al. (2014) }\end{array}$ \\
\hline $\begin{array}{l}\text { SBUV Merged Cohesive } \\
\text { VN8.6 }\end{array}$ & $\begin{array}{l}\text { Raw satellite product: } \\
\text { nadir-viewing instrument }\end{array}$ & 1978-2012 & ppmv & Wild and Long (2015) \\
\hline
\end{tabular}

the representation of the SOR in the ozone dataset being created for CMIP6 (Hegglin et al., 2016).

Given the potential application of the results described here for use in climate model simulations, it is prudent to briefly review the typical requirements of an ozone database for models by describing the CMIP5 dataset as a representative example (Cionni et al., 2011) (see also Bodeker et al., 2013). The CMIP5 ozone database provided monthly mean ozone mixing ratios on a regular latitude-pressure grid at a horizontal resolution of $5^{\circ} \times 5^{\circ}$ (long $\times$ lat) on 24 pressure levels covering 1000-1 hPa for the period 1850-2100. Data were provided on the following pressure levels: 1000,850 , 700, 600, 500, 400, 300, 250, 200, 150, 100, 80, 70, 50, 30, $20,15,10,7,5,3,2,1.5$, and $1 \mathrm{hPa}$. Stratospheric ozone data (at $p \leq 300 \mathrm{hPa}$ ) were given as zonal mean values. Therefore, any description of the SOR must fulfil these (or similar) criteria to be viable for use in climate models (i.e. global coverage at monthly mean resolution and with sufficient vertical and horizontal resolution throughout the stratosphere).

\section{Ozone datasets}

The satellite ozone datasets examined in this study are summarized in Table 1. A detailed overview of their spatial and temporal sampling characteristics and, where appropriate, their merging procedures is provided by Tummon et al. (2015) and references therein. Their main properties are briefly summarized below. Since our goal is to extract a signal with power on quasi-decadal timescales, it is desirable to use the longest available time series, and we therefore analyse all datasets over their full periods. For the longest record considered, this amounts to approximately three solar cycles.

\subsection{SAGE II-based records}

The SAGE II record forms the basis of many long-term ozone datasets (see, e.g., Tummon et al., 2015). As a limbviewing instrument, the spatial and temporal sampling of SAGE is fairly sparse, with a given latitude measured approximately once per month; however, it is recognized as having good long-term stability and a vertical resolution of $\sim 1 \mathrm{~km}$ in the stratosphere, which are characteristics that are likely to be important for analysing the SOR. We use zonal and monthly mean ozone data from October 1984 to August 2005 provided through the WCRP/SPARC Data Initiative (SDI) (Tegtmeier et al., 2013).

The native retrieval coordinate of SAGE II is units of ozone number densities on altitude levels; data are postprocessed to volume mixing ratios (vmr) on pressure levels using temperatures from a meteorological reanalysis dataset. The SAGE II retrieval algorithm was recently updated as part of the version 7.0 release (Damadeo et al., 2013). The SOR in SAGE II v6.2 data has been discussed in a number of studies: e.g. Randel and Wu (2007), Soukharev and Hood (2006), and Gray et al. (2009) for mixing ratios and Remsberg and Lingenfelser (2010) for number densities. Here we compare the SOR in the latest v7.0 release to the previous v6.2 in units of number densities and mixing ratios. It is important to conduct this comparison in both sets of coordinates because the temperature record used to convert SAGE II to mixing ratios was changed between v6.2 and v7.0 from National Meteorological Center/National Center for Environmental Prediction (NMC/NCEP) data to Modern Era-Retrospective Analysis for Research and Applications version 1 (MERRA-1) reanalysis data. The impact of this change on the SOR in 
SAGE II datasets has not been previously evaluated and is described in Sect. 4.1.

As a solar occultation instrument, SAGE II profiles can be categorized as a sunrise (SR) or sunset (SS) measurement. There are known variations in the relative number of SR/SS profiles over the SAGE II record. For example, SAGE II obtained profiles in two narrow latitude bands each day, 15 each at sunrise and sunset, but after November 2000 SAGE II measured only one profile per orbit at either SR or SS. These variations in SR/SS sampling have been shown to affect estimates of climatological ozone values due to diurnal cycle effects (Toohey et al., 2013) but could also affect temporal variability in monthly mean ozone values. To account for the possible effects of these sampling issues on the estimation of the SOR, we add an additional term to the multiple linear regression model for SAGE II data that represents the fraction of SR to total (SR $+\mathrm{SS}$ ) profiles used to generate each monthly mean data point (see Sect. 3).

The SAGE II mission stopped measuring in 2005. Since then several satellite instruments have continued to measure ozone, and there are now a number of combined datasets that have extended SAGE II to near the present day. These datasets were recently analysed as part of the WCRP/SPARC $\mathrm{SI}^{2} \mathrm{~N}$ activity to evaluate long-term ozone trends (see Tummon et al., 2015, and references therein) and include SWOOSH (Stratospheric Water and OzOne Satellite Homogenized) (Davis et al., 2016), GOZCARDS (Global OZone Chemistry And Related trace gas Data records for the Stratosphere) (Froidevaux et al., 2015), SAGE-GOMOS (Global Ozone Monitoring by Occultation of Stars) (Kyrölä et al., 2013; Penckwitt et al., 2015), and SAGE-OSIRIS (Optical Spectrograph and Infrared Imager System) (Bourassa et al., 2014). As mentioned above, SAGE II mixing ratios are produced by the conversion of number densities using an independent temperature record. The uncertainties in the SOR that result from using different stratospheric temperature records for this conversion are demonstrated in Sect. 4.1. This leads us to focus our analysis of the SOR on the extended SAGE II records that provide ozone as number densities and are therefore less dependent on the conversion issues that accompany the choice of a particular temperature record (see Sect. 4.1.2). Since SWOOSH and GOZCARDS currently only provide ozone mixing ratios, we do not analyse them here.

The three extended ozone datasets all include SAGE II v7.0 number densities. Differences in the SOR between the datasets may therefore arise as a result of the more recent measurements used to extend SAGE II and/or from the methods used to merge the different satellite records. Two of the datasets extend SAGE II using GOMOS, which flew on the ENVISAT satellite and covers 2002-2011, but take different approaches for combining the two records. Kyrölä et al. (2013) use GOMOS as a reference and adjust SAGE II sunrise and sunset profiles separately at each latitude and altitude; this dataset will be referred to as SAGE-GOMOS 1 .
Conversely, Penckwitt et al. (2015) use SAGE II as a reference and adjust GOMOS data using seasonally varying offsets at each latitude and altitude; this dataset will be referred to as SAGE-GOMOS 2. The third dataset analysed extends SAGE II using OSIRIS data and covers 19842013 (Bourassa et al., 2014; Sioris et al., 2014). Latitudeand altitude-dependent offsets are calculated for the deseasonalized data during the instrument overlap period (January 2002-August 2005), and the OSIRIS data are adjusted to produce a consistent combined SAGE II and OSIRIS time series.

\subsection{SBUV-based records}

In addition to SAGE II, the other main long-term internally calibrated satellite ozone dataset is comprised of data from the Backscatter Ultraviolet Radiometer (BUV) and Solar Backscatter Ultraviolet Radiometer (SBUV) instruments on board Nimbus satellites and the SBUV/2 instruments on various National Oceanic and Atmospheric Administration (NOAA) satellites. Data are available as mixing ratios on pressure levels from January 1970 to near the present day. As nadir-viewing instruments, the BUV/SBUV records have more frequent global coverage than the limb-viewing SAGE II, but their vertical resolution is at least 1 order of magnitude poorer at pressures greater than $\sim 15 \mathrm{hPa}$, rendering it more difficult to resolve detailed ozone structures in the mid and lower stratosphere. Since the entire BUV/SBUV record is comprised of multiple records from different satellites, inter-instrument biases and drifts must also be accounted for to produce a homogenized record.

We analyse zonal and monthly mean data from SBUVMOD VN8.0 and the latest release SBUV VN8.6 (McPeters et al., 2013; Bhartia et al., 2013), thereby complementing previous analyses of the SOR (e.g. Soukharev and Hood, 2006). SBUVMOD VN8.0 covers the period 1970-2009 and was downloaded from http://acd-ext.gsfc.nasa.gov/Data_services/merged/data/ sbuv.70-09.za.v8_prof.vmr.rev1.txt.

Two versions of the SBUV VN8.6 record have been produced so far: the SBUVMOD VN8.6 dataset from NASA, which covers 1970-2012 (Frith et al., 2014), and the SBUV Merged Cohesive dataset from NOAA, which covers 19782012 (Wild and Long, 2015). These are identical to the datasets analysed as part of the $\mathrm{SI}^{2} \mathrm{~N}$ activity (e.g. Tummon et al., 2015). The two SBUV VN8.6 datasets contain some differences in the data that are included from different instruments within a particular period (see Fig. 1 in Tummon et al., 2015) and in the methods for averaging and merging these data. SBUV Merged Cohesive VN8.6 uses data from a single instrument in any time period; the individual records are then bias-corrected to produce a continuous record (Wild and Long, 2015). In contrast, SBUVMOD VN8.6 is constructed by averaging all available data within a particular time window (Frith et al., 2014). The SBUVMOD datasets extend 
back to 1970 by including data from the BUV instrument on Nimbus 4 from 1970 to 1976, whereas the SBUV Merged Cohesive dataset starts from 1978 with the first SBUV instrument on Nimbus 7.

\section{The multiple linear regression model}

Following numerous earlier studies (e.g. Frame and Gray, 2010; Soukharev and Hood, 2006; Mitchell et al., 2015a), the SOR is diagnosed using multiple linear regression (MLR); this technique enables the signals associated with different forcings within a single time series to be separated.

The ozone data are first deseasonalized by removing the long-term monthly mean at each latitude and pressure (or altitude). As in past studies, we then perform an MLR analysis on the time series of monthly mean ozone anomalies at each location, $\mathrm{O}_{3}^{\prime}(t)$, to diagnose the 11-year solar cycle component:

$$
\begin{aligned}
\mathrm{O}_{3}^{\prime}(t)= & A \times \mathrm{F} 10.7(t)+B \times \mathrm{CO}_{2}(t)+C \times \operatorname{EESC}(t) \\
& +D \times \operatorname{ENSO}(t)+E \times \mathrm{QBO}_{A}(t)+F \\
& \times \mathrm{QBO}_{B}(t)+r(t)
\end{aligned}
$$

where $r(t)$ is a residual. The analysis mainly focuses on annual-mean signals, which are calculated by regressing all months as a single time series.

The monthly basis functions are the $\mathrm{F} 10.7 \mathrm{~cm}$ radio solar flux (http://lasp.colorado.edu/lisird/tss/noaa_radio_flux. html), the $\mathrm{CO}_{2}$ concentration at Mauna Loa (http://www. esrl.noaa.gov/gmd/ccgg/trends/data.html), the equivalent effective stratospheric chlorine (EESC), the Nino 3.4 index calculated from the Extended Reconstructed Sea Surface Temperature (ERSST) v3b dataset (http://www.esrl.noaa.gov/ $\mathrm{psd} / \mathrm{data} / \mathrm{gridded} /$ data.noaa.ersst.html), and two quasi biennial oscillation (QBO) indices representing tropical zonal winds at 30 and $50 \mathrm{hPa}$ (http://www.cpc.ncep.noaa.gov/data/ indices/). Figure 1 shows example time series of these indices from 1970 to 2015 in arbitrary units. The coefficients $A-F$ are calculated using linear least squares regression.

The El Niño-Southern Oscillation (ENSO) is the main regressor for which a lagged response in stratospheric ozone might be expected; however, we find that the SOR is not sensitive to lagging the ozone anomalies with respect to the Nino 3.4 index by $0-12$ months. We therefore do not include any lags in Eq. (1). We have also tested the sensitivity of the diagnosed SOR to the use of a spatially varying EESC field using output from the UM-UKCA chemistry-climate model REF-C1 CCMI integration. However, this has virtually no effect on the SOR compared to the use of a single EESC time series for all locations, and we therefore adopt the latter approach for simplicity.

We do not include a volcanic term in the MLR model but instead choose to exclude data from the 2-year periods following the two major tropical volcanic eruptions during the analysis epoch: El Chichón (data excluded from
April 1982 to March 1984) and Mt Pinatubo (data excluded from June 1991 to May 1993). These periods are excluded from the analysis for two reasons: firstly, some of the ozone datasets analysed implicitly exclude data in these periods for quality control purposes, whereas others do not. For consistency, we therefore exclude these periods for all datasets. Secondly, removing these periods reduces the likelihood of aliasing between volcanic and solar signals, which can be an issue within relatively short climate data records (Chiodo et al., 2014).

We adopt the widely used F10.7 $\mathrm{cm}$ solar flux as a proxy for solar activity in the MLR model. This is a more appropriate measure for variations in the UV spectral region, the key driver of the SOR, than other indices such as TSI (Gray et al., 2010); however, it should be noted that the F10.7 cm flux is not a direct measurement of UV variability but rather is a proxy for variations at these wavelengths. Throughout the manuscript the SOR is expressed as percent ozone change per 130 solar flux units $\left(1 \mathrm{SFU}=10^{-22} \mathrm{Wm}^{-2} \mathrm{~Hz}^{-1}\right)$ to represent the difference between the 11-year solar cycle maximum and minimum.

The $95 \%$ confidence intervals on the SORs are estimated by

$A \pm t_{\alpha / 2, n-(k+1)} \sqrt{C_{A A}}$,

where $A$ is the solar regression coefficient in Eq. (1), $t_{\alpha / 2, n-(k+1)}$ is the critical $t$ value at a confidence level, $\alpha$, of 0.05 with degrees of freedom $n-(k+1)$, where $n$ is the number of data points in the regression, $k$ is the number of regressors, and $C_{A A}$ is the variance of the estimated solar regression coefficient $A$.

As mentioned in Sect. 2.1, the SAGE II record is affected by irregular SR and SS sampling as a function of time. This could introduce spurious variability in the monthly mean ozone values, particularly in the upper stratosphere, as a result of the diurnal cycle in ozone. However, many previous regression studies of SAGE II data have not accounted for the non-stationarity in SR/SS sampling (e.g. Randel and Wu, 2007). Here, we account for this by including an additional term in Eq. (1) that quantifies the ratio between the number of SR and the total (SR $+\mathrm{SS})$ number of profiles used to produce each monthly mean SAGE II data point; this index can take values between 0 and 1 . An example of this index for the SAGE II v7.0 dataset at $1 \mathrm{hPa}$ averaged over the tropics $\left(30^{\circ} \mathrm{S}-30^{\circ} \mathrm{N}\right)$ is shown in Fig. 2.

One important issue for MLR analysis is the handling of possible autocorrelation in the regression residuals and its effects on the estimation of statistical uncertainties. A DurbinWatson test does not reveal significant autocorrelation in the regression residuals at most locations; however, this is likely to be because there is a considerable fraction of missing data points at any one location in many of the datasets analysed. In the analysis of chemistry-climate model simulations in Part 2 of this study, for which there is complete spatial and 
(a) SOLAR
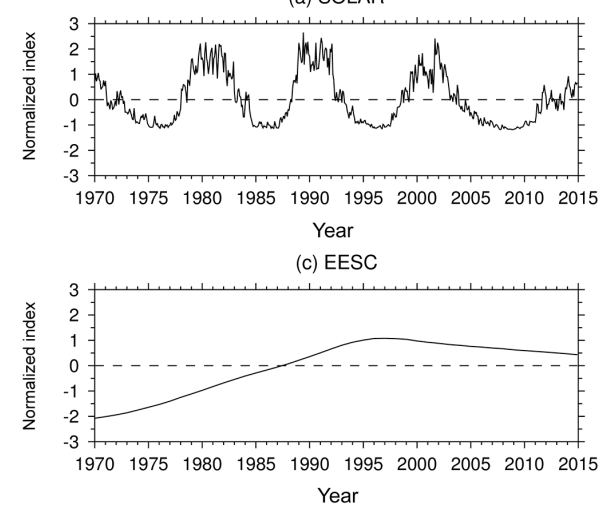

(e) QBO A

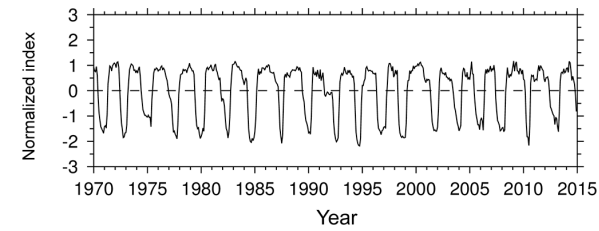

(b) $\mathrm{CO}_{2}$

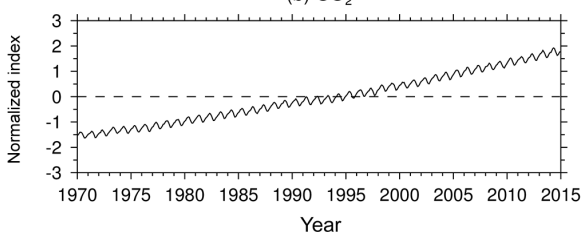

(d) ENSO

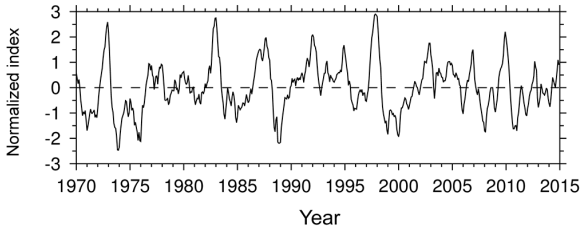

(f) QBO B

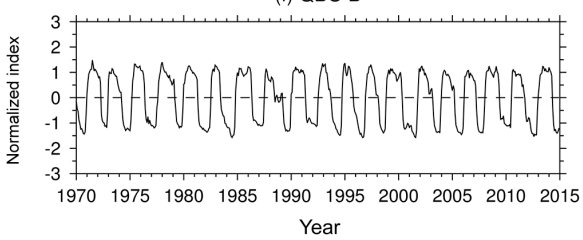

Figure 1. Time series of the six basis functions used in the MLR model. (a) Solar forcing based on F10.7 cm solar radio flux; (b) a trend term based on the monthly $\mathrm{CO}_{2}$ concentration at Mauna Loa; (c) equivalent effective stratospheric chlorine; (d) the Nino 3.4 index for ENSO; (e, f) two QBO indices based on tropical zonal winds at 50 and $30 \mathrm{hPa}$. The time series are in units of standard deviation and the time period is 1970-2015. A volcanic term is not included because the 2-year periods following the two major tropical volcanic eruptions in this epoch (El Chichón and Mt Pinatubo) are excluded from the regression analysis.

Sampling of SR/(SR+SS) profiles for SAGE II v7.0 vmr

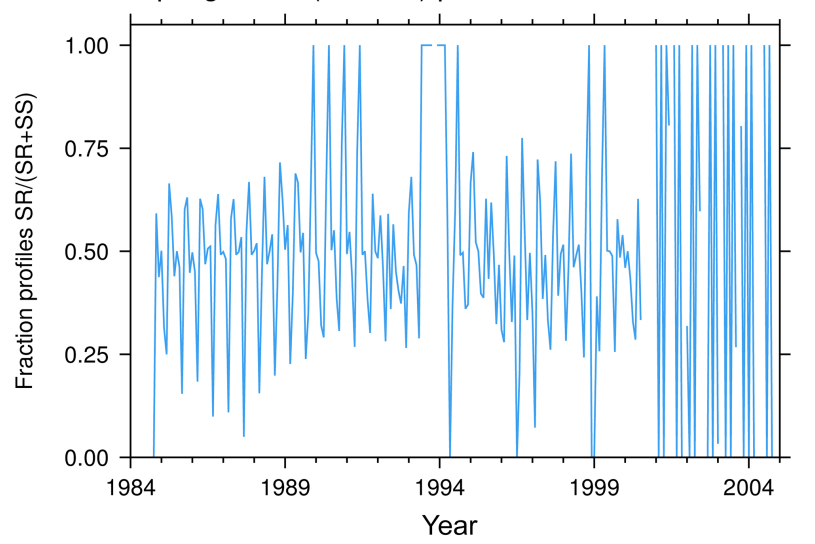

Figure 2. Time series of the fraction of sunrise to total (sunrise + sunset) profiles used to generate monthly mean ozone values in the tropics $\left(30^{\circ} \mathrm{S}-30^{\circ} \mathrm{N}\right)$ at $1 \mathrm{hPa}$ for the SAGE II v7.0 vmr dataset.

temporal sampling, a Durbin-Watson test reveals significant serial correlation in the regression residuals in many locations for lags of 1 and 2 months, particularly in the lower stratosphere and mesosphere. This autocorrelation can lead to spurious overestimation of the statistical significance of the regression coefficients, and we therefore include an autoregressive term in the MLR model. Given the significant serial correlation of the residuals in the chemistry-climate models at up to 2 months' lag in some regions, a secondorder autoregressive noise process (AR2) is used, which assumes the residuals $r(t)$ have the following form:

$r(t)=\operatorname{ar}(t-1)+b r(t-2)+w(t)$,

where $a$ and $b$ are constants and $w(t)$ is a white noise process; this is the same approach employed in the recent SPARC SI ${ }^{2} \mathrm{~N}$ analysis of ozone trends (Tummon et al., 2015; Harris et al., 2015). The inclusion of this term has a very minor effect on the results for the observational datasets in Part 1 but has a greater effect for the model results in Part 2. We therefore include it in the analysis here for consistency between both parts of the study.

\section{Results}

\subsection{The SOR in SAGE II datasets}

Figure 3 shows time series of monthly and tropical $\left(30^{\circ} \mathrm{S}-\right.$ $30^{\circ} \mathrm{N}$ ) mean percent ozone anomalies from 1984 to 2004 at select stratospheric levels for SAGE II v6.2 and v7.0 in units of mixing ratios (on pressure surfaces) and number densities (on approximately equivalent altitude surfaces). Data are only plotted where at least half of the points within the tropical band have values in a given month. The lowest panel shows the monthly F10.7 cm solar flux for reference. 

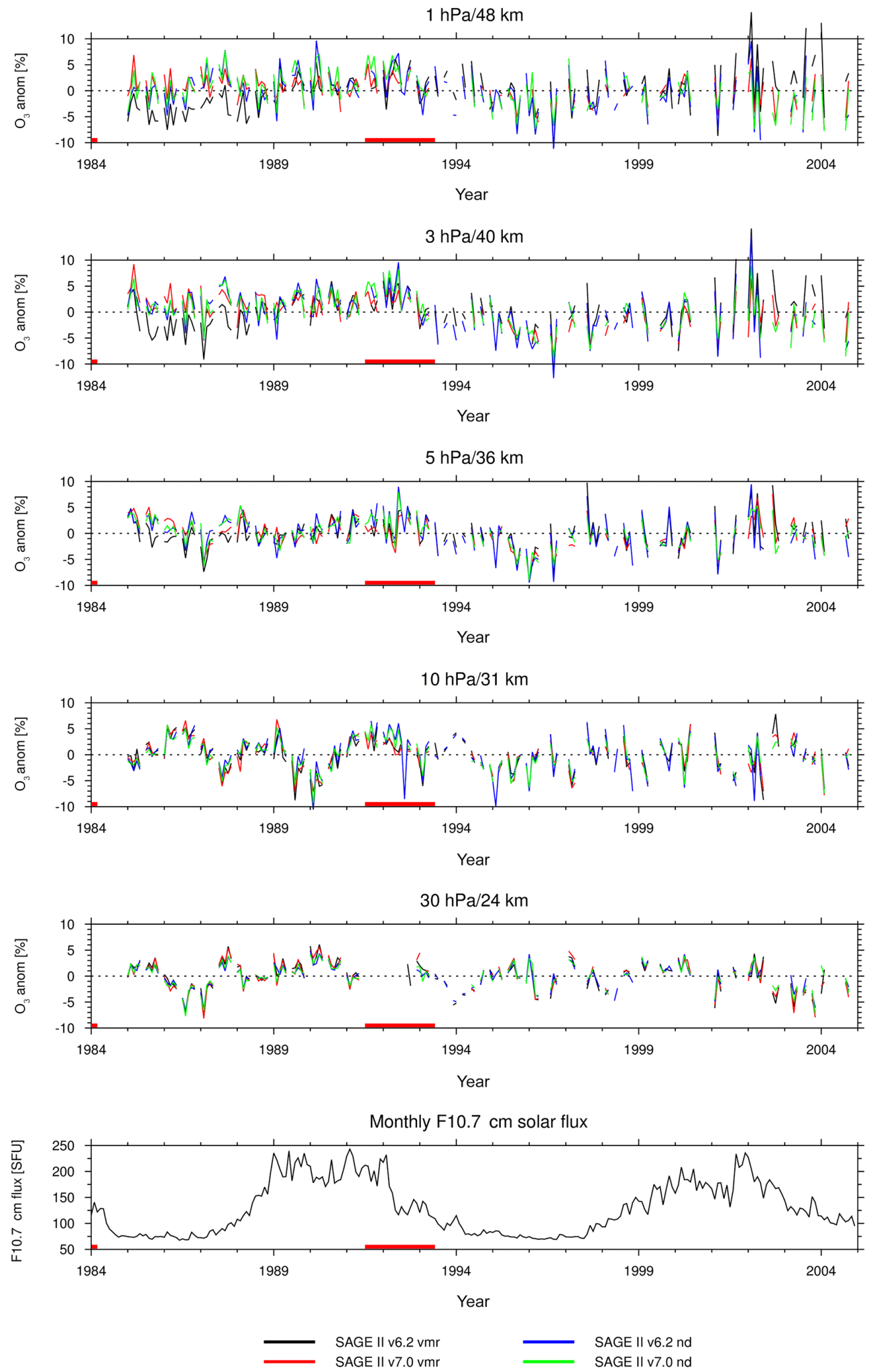

Figure 3. Time series of percent tropical mean $\left(30^{\circ} \mathrm{S}-30^{\circ} \mathrm{N}\right)$ ozone anomalies for $1984-2004$ at (a) $1 \mathrm{hPa}(48 \mathrm{~km})$, (b) $3 \mathrm{hPa}(40 \mathrm{~km})$, (c) $5 \mathrm{hPa}(36 \mathrm{~km})$, (d) $10 \mathrm{hPa}(31 \mathrm{~km})$, and (e) $30 \mathrm{hPa}(24 \mathrm{~km})$. Data are shown for SAGE II v6.2 volume mixing ratios (vmr) (black), SAGE II v7.0 vmr (red), SAGE II v6.2 number densities (nd) (blue), and SAGE II v7.0 nd (green). The thick red lines denote the periods excluded from the MLR analysis following major tropical volcanic eruptions. The bottom panel shows the F10.7 cm solar flux for reference. 

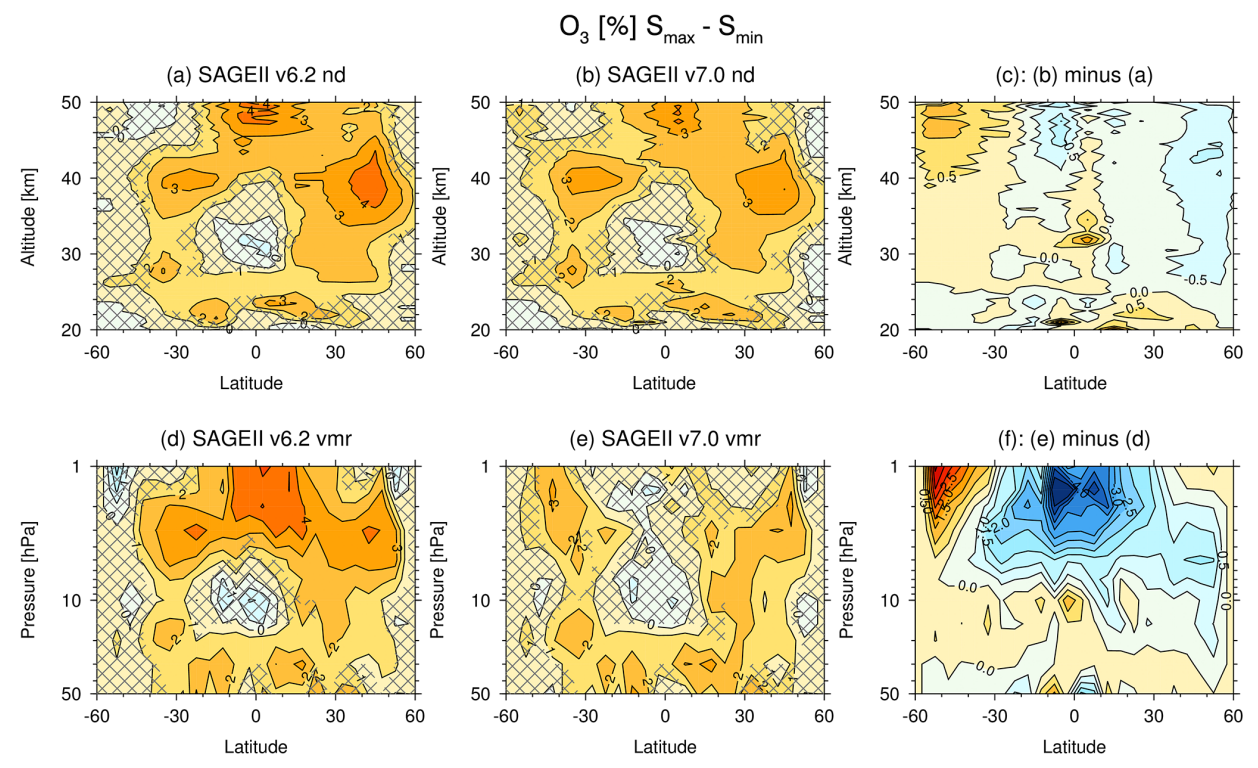

Figure 4. The percent (\%) annual solar-ozone response (SOR) (per 130 SFU) for the (a, d) SAGE II v6.2 data and (b, e) SAGE II v7.0 data in terms of $(\mathbf{a}, \mathbf{b})$ number-density-altitude coordinates and $(\mathbf{d}, \mathbf{e})$ volume-mixing-ratio-pressure coordinates. Panel (c) shows (b) minus (a), and panel (f) shows (e) minus (d). The contour interval is $1 \%$ in panels $(\mathbf{a}, \mathbf{b}, \mathbf{d}, \mathbf{e})$ and $0.5 \%$ in panels $(\mathbf{c}, \mathbf{f})$. The hatching denotes regions where the SOR is not statistically distinguishable from 0 at the $95 \%$ confidence level.

The anomalies in the two ozone number density datasets (blue and green lines) are in close agreement in the midstratosphere $(24,31$, and $36 \mathrm{~km})$ both in terms of highfrequency fluctuations and long-term changes. At $31 \mathrm{~km}$, there are ozone variations that are consistent with a QBO influence. At 36 and $40 \mathrm{~km}$, there are variations that are visibly in phase with the solar cycle, with relatively high ozone values from 1989 to 1992 during the solar cycle 22 maximum and lower ozone values from 1994 to 1998 during the cycle minimum. The data show greater variance in the early and later parts of the records, and fluctuations in phase with the solar cycle are not evident from the time series alone.

The two SAGE II ozone mixing ratio datasets (black and red lines) are also in reasonable agreement for long-term changes in the mid-stratosphere $(10$ and $30 \mathrm{hPa})$. However, in the upper stratosphere $(1$ and $3 \mathrm{hPa})$, there are substantial differences in both short- and long-term variations. For example, SAGE II v6.2 (black line) shows persistent negative anomalies in the early part of the record which are not evident in v7.0 (red line). These coincide with the 11-year solar cycle 21 minimum from 1985 to 1988 . Furthermore, in the latter part of the record, v6.2 shows relatively largeamplitude fluctuations with mean positive anomalies from 2002 to 2004, which coincide with the peak and subsequent declining phase of solar cycle 23 . Thus, there are differences in the evolution of ozone between the two SAGE II mixing ratio datasets, particularly in the upper stratosphere. Overall, the two versions of SAGE II number densities are in closer agreement than the mixing ratio data.
Figure $4 \mathrm{a}$ and $\mathrm{b}$ show latitude-altitude plots of the annual mean SOR for SAGE II v6.2 and v7.0 number densities, respectively. The $95 \%$ confidence intervals for the SORs in Fig. 4 expressed as percent ozone anomalies are shown in Fig. 5. The SORs in Fig. 4a and b are generally consistent for the two datasets and show positive values of $2-$ $4 \%$ across the tropical and subtropical stratosphere, except for a region of small $(<1 \%)$ negative values at $30 \mathrm{~km}$ in the tropics. There is a relative maximum in the SOR of 3$4 \%$ in the tropics at $50 \mathrm{~km}$ and two off-equatorial peaks of a similar magnitude at $\sim 40 \mathrm{~km}$ and $\pm 35^{\circ}$. These findings are consistent with Remsberg and Lingenfelser (2010) and Remsberg (2014), who found similar 11-year solar-like signals in tropical upper-stratospheric ozone number densities in SAGE II v6.2 and v7.0. The confidence intervals for the SORs in Fig. 5a and b show the largest uncertainty at the equator at $\sim 45 \mathrm{~km}$, which is close to a maximum in the SOR. The uncertainties between 35 and $45 \mathrm{~km}$ are slightly larger in the northern subtropics compared to the southern subtropics. The uncertainties in the lower stratosphere between 22 and $28 \mathrm{~km}$ are smaller in magnitude, but this is partly because the SOR is also smaller here (note the confidence intervals are expressed as percent ozone to be directly comparable to Fig. 4). Overall, the $95 \%$ confidence intervals are around 30 $50 \%$ of the magnitude of the "best-estimate" SOR in Fig. 4a and $\mathrm{b}$, indicating that there are considerable uncertainties in the SOR in the SAGE II number density datasets. This has implications for understanding the contribution of the SOR to the atmospheric response to the solar cycle. 
(a) SAGEIl v6.2 nd

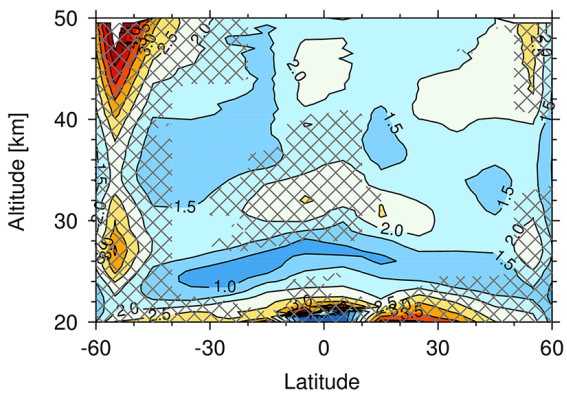

(c) SAGEIl v6.2 vmr

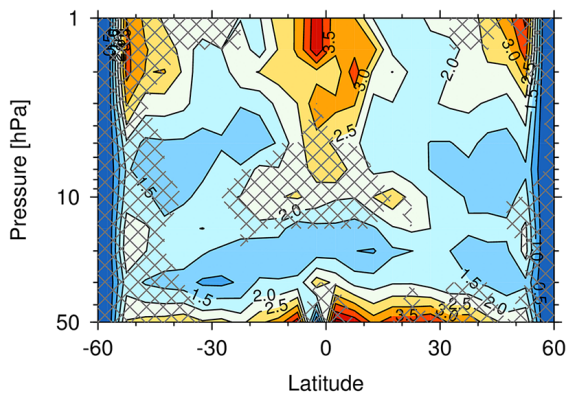

(b) SAGEIl v7.0 nd

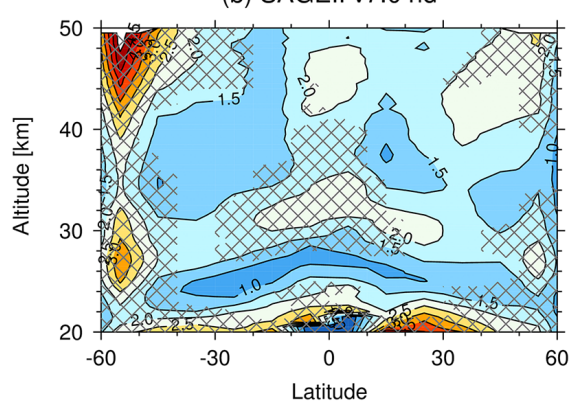

(d) SAGEII v7.0 vmr

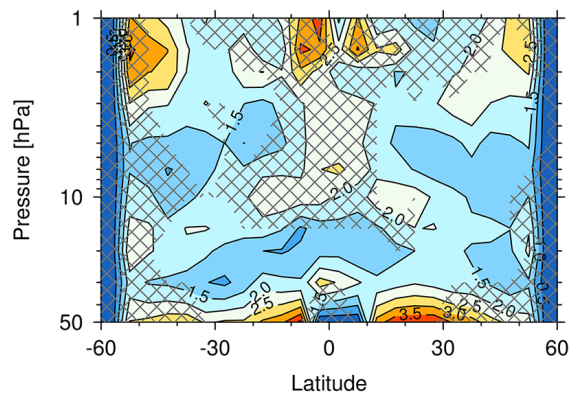

Figure 5. The $95 \%$ confidence intervals (CI) on the SORs (SOR \pm CI) shown in Fig. 4 for the (a, c) SAGE II v6.2 data and (b, d) SAGE II v7.0 data in terms of (a, b) number-density-altitude coordinates and (c, d) volume-mixing-ratio-pressure coordinates. The contour interval is $0.5 \%$. The hatching is as in Fig. 4 .

Figure $4 \mathrm{c}$ and $\mathrm{d}$ show equivalent plots to Fig. $4 \mathrm{a}$ and $\mathrm{b}$ for SAGE II v6.2 and v7.0 in coordinates of mixing ratios on pressure levels. The SORs between $\sim 50$ and $10 \mathrm{hPa}$ are very similar in the two versions and strongly resemble Fig. 4a and $\mathrm{b}$, with a positive SOR in the tropical lower stratosphere of $\sim 1-2 \%$. The structures of the SOR between 20 and $\sim 7 \mathrm{hPa}$ are also similar, with subtropical maxima of $1-2 \%$ and a distinct equatorial minimum. However, the SORs in the upper stratosphere are markedly different between v6.2 and v7.0. Polewards of $\pm 20^{\circ}$ the structure of the SORs are similar in both datasets, but the magnitude is $\sim 1 \%$ larger in v6.2. In the tropics, the v6.2 mixing ratio data show a large peak in the SOR in the upper stratosphere of up to $5 \%$, whereas the v7.0 data show a smaller SOR of $1 \%$ in this region.

The confidence intervals for the SAGE II mixing ratio SORs in Fig. 5c and d are generally similar to those for number densities, with the exception of the uncertainties being considerably larger in the tropical upper stratosphere in both datasets but particularly in SAGE II v6.2. The relatively large uncertainties in the best estimate of the SOR would feed through to similar uncertainties in the contribution of the SOR to the atmospheric response to the 11-year solar cycle (Gray et al., 2009; Shibata and Kodera, 2005). It is therefore important to understand the causes of the differences in SOR between the SAGE II v6.2 and v7.0 mixing ratio datasets, since this presents a limitation for understanding and simulating the climate response to solar forcing (e.g. Ermolli et al., 2013; Mitchell et al., 2015b). This is explored in the next section.

\subsubsection{Differences in NMC/NCEP and MERRA-1 stratospheric temperature records}

Since the two versions of SAGE II show comparable SORs for number densities, the differences between Fig. $4 \mathrm{c}$ and d must be related to the conversion of SAGE II data to ozone mixing ratios. As described in Sect. 2, SAGE II v6.2 employed NMC/NCEP temperature data for this conversion, but this was changed to MERRA-1 for v7.0 (see Damadeo et al., 2013, for details). The differences in the SOR in the upper stratosphere would therefore appear to be related to the use of different temperature records in the conversion. It is known that the evolution of stratospheric temperatures in some reanalyses show unphysical variability and trends (Mitchell et al., 2015a), and these have been corrected for in some solar-climate studies (e.g. Frame and Gray, 2010; Hood et al., 2015). However, the effect of temperatures on the SOR in SAGE II data has not been considered previously. Indeed, spurious variations in stratospheric temperatures in reanalyses datasets, which are introduced through changes in the observing system over time, could mask or enhance the SOR in SAGE II ozone mixing ratios. 
Figure 6 shows time series of annual and tropical mean temperature anomalies at select stratospheric levels (1, 2, 5, $10,30 \mathrm{hPa}$ ) for the NMC/NCEP and MERRA- 1 datasets. The NMC/NCEP temperatures are those provided with the published SAGE II data files and cover 1985-2003. MERRA1 data were downloaded for 1979-2013 from the NASA GFSC website. At $30 \mathrm{hPa}$, the evolution of the two temperature records is nearly identical during the period of overlap, with a long-term cooling trend of $\sim 0.6 \mathrm{~K} \mathrm{decade}^{-1}$ that is strongly connected to an apparent stepwise cooling of $\sim 2 \mathrm{~K}$ between 1992 and 1994. However, at pressures less than $30 \mathrm{hPa}$ there are substantial differences between the records. The NMC/NCEP data show exceptional behaviour between 2000 and 2003. At $1 \mathrm{hPa}$, there is a warming of more than $3 \mathrm{~K}$ over this short period, which is coincident with a warming of $\sim 1 \mathrm{~K}$ at $2 \mathrm{hPa}$. In contrast, at 5 and $10 \mathrm{hPa}$ there is a cooling of more than 4 and $2 \mathrm{~K}$, respectively, over this period. The magnitude and vertical structure of these changes in the NMC/NCEP record seems too inexplicable as to be related to any physical process, particularly when compared to the variations found in the remainder of the record. Some of these issues may be related to the method used to construct the NMC/NCEP temperature record itself. NCEP reanalysis data were only available for pressures greater than $10 \mathrm{hPa}$, requiring the addition of operational analyses to extend the data to the stratopause. Data from an atmospheric model was used to further extend the temperature data to the mesosphere, but these levels are not considered here (see, e.g., Damadeo et al., 2013, for more details). Regardless of the exact cause, it seems likely that some of the temperature variations in the NMC/NCEP record are spurious, and this may impact on the diagnosed SOR in the SAGE II v6.2 mixing ratio data.

The temperature variations in MERRA-1 over the period 1985-2003 are generally smaller in magnitude than in NMC/NCEP, with the exception of a marked cooling at $1 \mathrm{hPa}$ of $\sim 3 \mathrm{~K}$ between 2001 and 2003, which is opposite to what is seen in NMC/NCEP. This cooling in MERRA-1 leads the decline in solar forcing during the downward phase of solar cycle 23 by around a year and is also larger in amplitude than typical solar signals in temperature at this level (Mitchell et al., 2015a). However, the sign is at least consistent with the expected tendency of upper-stratospheric temperatures during the declining phase of the solar cycle.

A valid question is which representation of past stratospheric temperatures is likely to be most realistic. Mitchell et al. (2015a) compared MERRA-1 to Stratospheric Sounding Unit (SSU) satellite data and found considerable differences in upper-stratospheric temperature variability between the two records. However, the NMC/NCEP data show a longterm warming trend in the upper stratosphere, which is opposite to the cooling expected from increasing atmospheric $\mathrm{CO}_{2}$ and declining ozone abundances over this period. Both records therefore appear to exhibit differences compared to observed stratospheric temperature changes.
The evolution of atmospheric temperatures will affect the geometric altitude of a given pressure surface, as well as the conversion from number density to mixing ratio. It is well known that cooling will lower the altitude of pressure surfaces, a so-called "atmospheric shrinking" effect. Therefore, the presence of cooling near the stratopause in MERRA-1 would tend to lead to a greater atmospheric shrinking than for the NMC/NCEP temperatures. Furthermore, the conversion from number density to mixing ratio is proportional to temperature, so a positive correlation between number density and temperature over the solar cycle would tend to increase the magnitude of the SOR on a given pressure surface. Figure 7 shows the annual mean solar cycle signals in stratospheric temperatures derived for the NMC/NCEP and MERRA-1 datasets over the period 1985-2003. Although the sign of the temperature signals are consistent in most regions, the maximum warming in the tropics at solar maximum occurs at $4 \mathrm{hPa}$ in MERRA- 1 as compared to $2 \mathrm{hPa}$ in NMC/NCEP. The peak magnitude of the solar cycle temperature response is also around $25 \%$ smaller in MERRA-1 compared to NMC/NCEP. The impact of these differences on the SOR in SAGE II mixing ratio data are explored in the next section.

\subsubsection{Dependence of SOR in SAGE II mixing ratios on temperature record}

To test the impact of the differences between NMC/NCEP and MERRA-1 temperatures on the SOR diagnosed in SAGE II mixing ratios, we perform our own conversion of the SAGE II v6.2 data from number densities to mixing ratios. Each monthly and zonal mean ozone profile is first converted to number densities on pressure levels using the hydrostatic equation, and then to mixing ratios on pressure levels using the ideal gas law. The MLR in Eq. (1) is then applied to these "post hoc" converted ozone mixing ratios to derive a SOR that can be compared to the published SAGE II mixing ratio datasets discussed above and shown in Fig. 4d and e.

As a first test, we convert SAGE II v6.2 number densities to mixing ratios using the full time series of temperatures from NMC/NCEP and MERRA-1 in turn. The SORs diagnosed from these post hoc converted datasets are shown in Fig. 8a and b for NMC/NCEP and MERRA-1, respectively, with the difference between them shown in Fig. 8c. These can be compared to Fig. $4 d-f$. We stress that differences in the SORs are to be expected, since in the published SAGE II datasets each ozone profile is converted separately before averaging is performed, whereas here we have converted the monthly, zonally, and latitudinally averaged ozone number density profiles.

The SOR in the post hoc converted data using NMC/NCEP temperatures (Fig. 8a) shows a qualitatively similar structure to Fig. 4d, but the peak magnitude is underestimated by $\sim 2 \%$ in the tropical upper stratosphere. The SOR in the data 

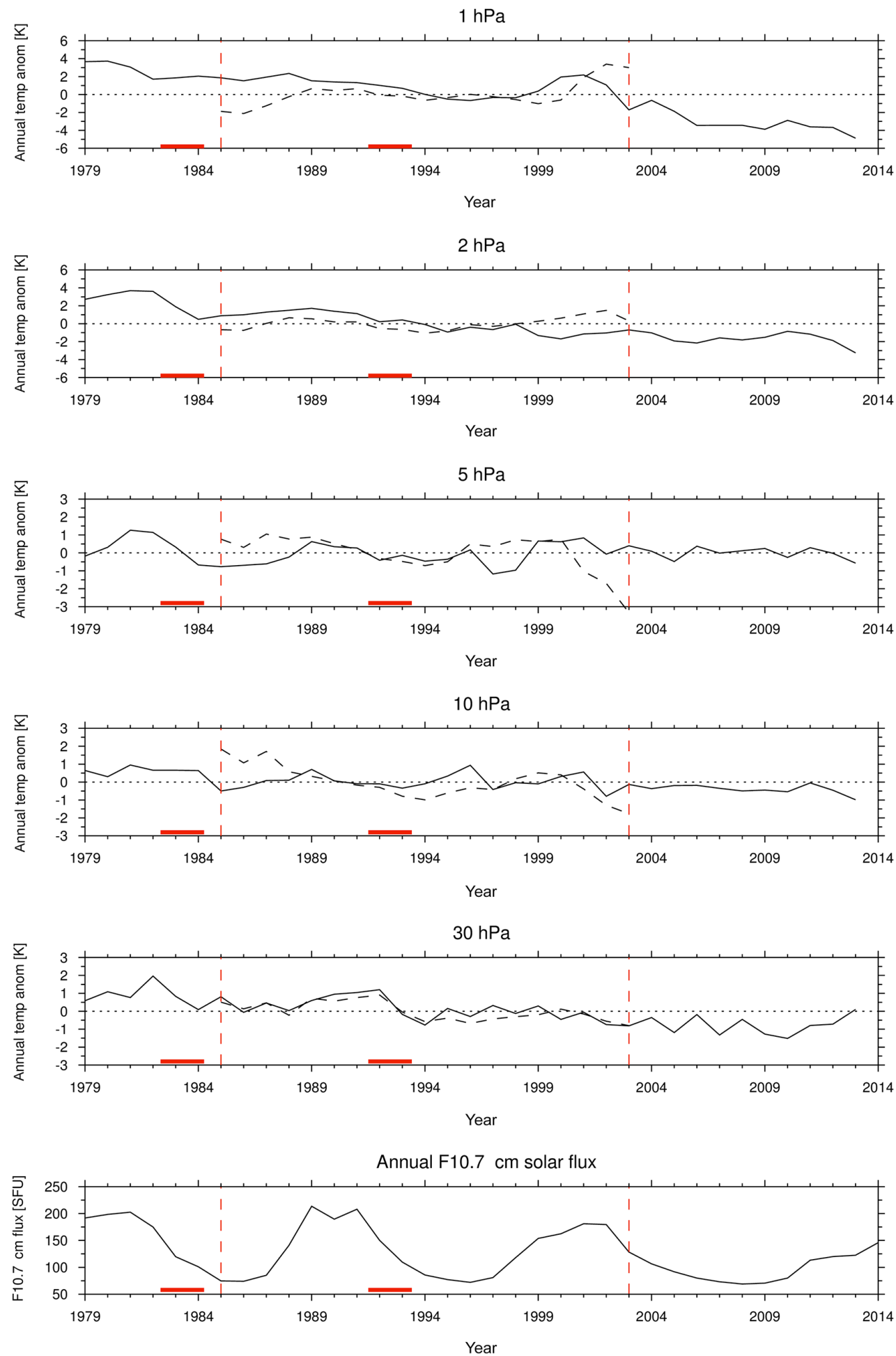

Figure 6. Time series of tropical and annual mean temperature anomalies (K) from the NMC/NCEP (dashed) and MERRA-1 (solid) datasets for (top to bottom) 1, 2, 5, 10, and $30 \mathrm{hPa}$. The time period is 1979-2013. The thick red lines denote the periods excluded from the MLR analysis following major volcanic eruptions. The bottom panel shows the $\mathrm{F} 10.7 \mathrm{~cm}$ solar flux for reference. The dashed vertical red lines show the period of overlap between the two datasets from which the solar cycle signals in stratospheric temperatures in Fig. 7 are derived. 
(a) NMC/NCEP

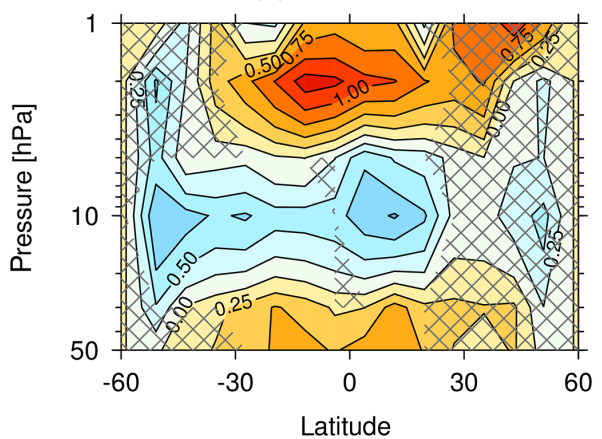

(b) MERRA-1

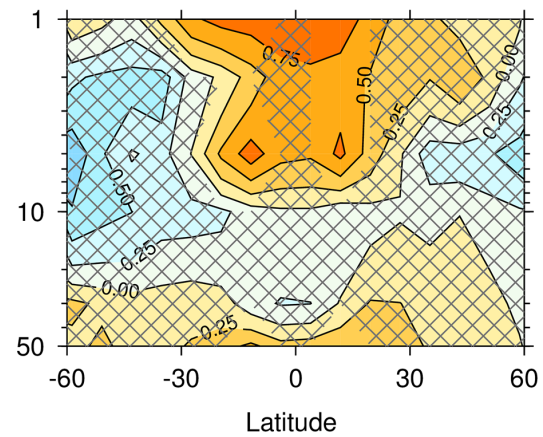

Figure 7. Eleven-year solar cycle signals in stratospheric temperature (K) from the (a) NMC/NCEP and (b) MERRA-1 datasets. Shading as in Fig. 4. The contour interval is $0.25 \mathrm{~K}$. These temperature fields are used in the post hoc conversion of SAGE II v6.2 number densities to mixing ratios (see Sect. 4.1.2 for details).

converted using MERRA-1 temperatures (Fig. 8b) compares more closely with the original SAGE II v7.0 vmr dataset (Fig. 4e). In particular, the reduced magnitude of the SOR in the tropical upper stratosphere is captured, which allows us to explore how differences in the linear trends and solar cycle signals in temperature between NMC/NCEP and MERRA-1 impact on the SOR.

Figure $8 \mathrm{~d}$ and e show the SOR for the SAGE II v6.2 data converted to mixing ratios using a monthly temperature climatology from MERRA-1 added to a latitude-heighttime-dependent linear trend and solar cycle term (see Fig. 7) extracted from either NMC/NCEP (Fig. 8d) or MERRA-1 (Fig. 8e). The difference between Fig. 8d and e is shown in Fig. $8 \mathrm{f}$ for reference. Figure $8 \mathrm{~d}-\mathrm{f}$ are very similar to Fig. $8 \mathrm{a}-\mathrm{c}$, indicating that the majority of the difference in SOR in Fig. 8c can be interpreted as being due to differences in long-term trends and solar cycle variability in temperatures between NMC/NCEP and MERRA-1. Further tests (not shown) show that the diagnosed SORs are not affected by the choice of base temperature climatology (i.e. MERRA-1 or NMC/NCEP).

The remaining panels Fig. 8g-i and $\mathrm{j}-1$ show equivalent results to Fig. 8d-f, but with the conversion of SAGE II v6.2 to mixing ratios performed with the MERRA-1 temperature climatology added to either the linear trend (Fig. 8g-i) or solar cycle (Fig. 8j-1) components of temperature variability from the two datasets. In both of these further tests, the SOR in the tropical upper stratosphere is larger for the SAGE II data converted using NMC/NCEP data (Fig. 8g, j). This indicates that both components of the temperature variability contribute to the differences in SOR in Fig. 8c.

In conclusion, the SORs in SAGE II v6.2 and v7.0 are much more consistent in terms of number densities on altitude surfaces than they are for mixing ratios on pressure surfaces. The differences in SORs in the latter occur particularly in the upper stratosphere, and these have been shown to be sensitive to the details of the temperature records used for conversion. The long-term warming trend in the upper stratosphere in NMC/NCEP data is at odds with the understanding of recent changes in stratospheric composition and its impact on temperatures (Randel et al., 2009); however, the peak of the solar cycle signal in stratospheric temperatures in MERRA-1 is at a lower altitude than predicted from theory and models. Recent analysis suggests that the relationship between ozone and temperature in the upper stratosphere that is anticipated from photochemical theory is more realistic for the SAGE II v7.0 mixing ratio data than for v6.2 (Dhomse et al., 2016). Nevertheless, there remain questions around which of the SAGE II mixing ratio datasets is likely to be most credible for diagnosing the SOR. These results raise issues around the representation of the SOR in the CMIP5 ozone database, which was largely based on SAGE II v6.2 mixing ratios (Cionni et al., 2011; see also Maycock et al., 2016).

\subsection{The SOR in extended SAGE II datasets}

Given the uncertainties in the SOR diagnosed for SAGE II mixing ratios discussed above, we focus our analysis of the extended SAGE II records on the three $\mathrm{SI}^{2} \mathrm{~N}$ datasets that are currently available as number densities (see Sect. 2.1): SAGE-GOMOS 1, SAGE-GOMOS 2, and SAGE-OSIRIS. Extending SAGE II using these more recent measurements increases the number of data points included in the MLR model by almost a factor of 2 in the tropics and by $\sim 50 \%$ in the subtropics (see Figs. S1 and S2 in the Supplement). Figure 9 shows time series of monthly tropical percent ozone anomalies at select altitudes for the three $\mathrm{SI}^{2} \mathrm{~N}$ datasets. The datasets do not agree perfectly over the SAGE II era (1984-2004) because the anomalies are defined relative to the entire time series, but overall they show similar behaviour to SAGE II v7.0 number densities (green line) in Fig. 3, as expected. In the post-2004 period, where either GOMOS or OSIRIS data are included, the datasets show generally consistent behaviour in the mid-stratosphere dur- 

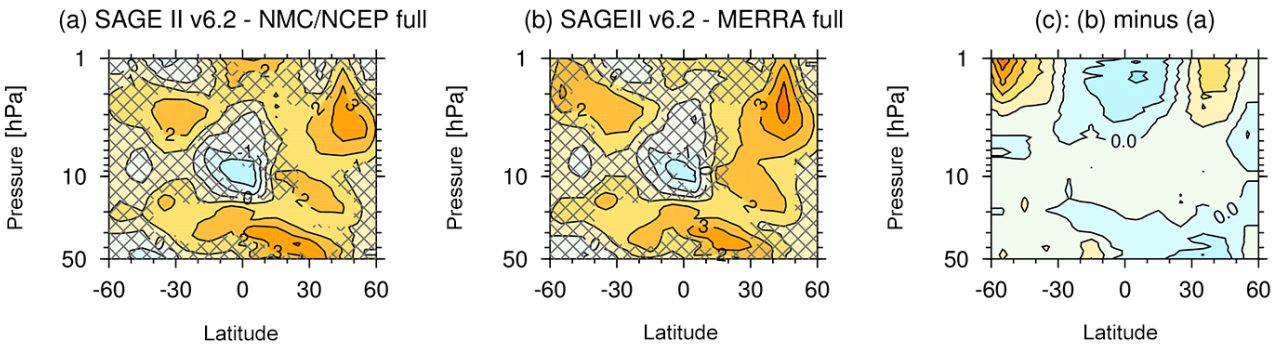

(d) SAGEIl v6.2 - NMC/NCEP sol+trend
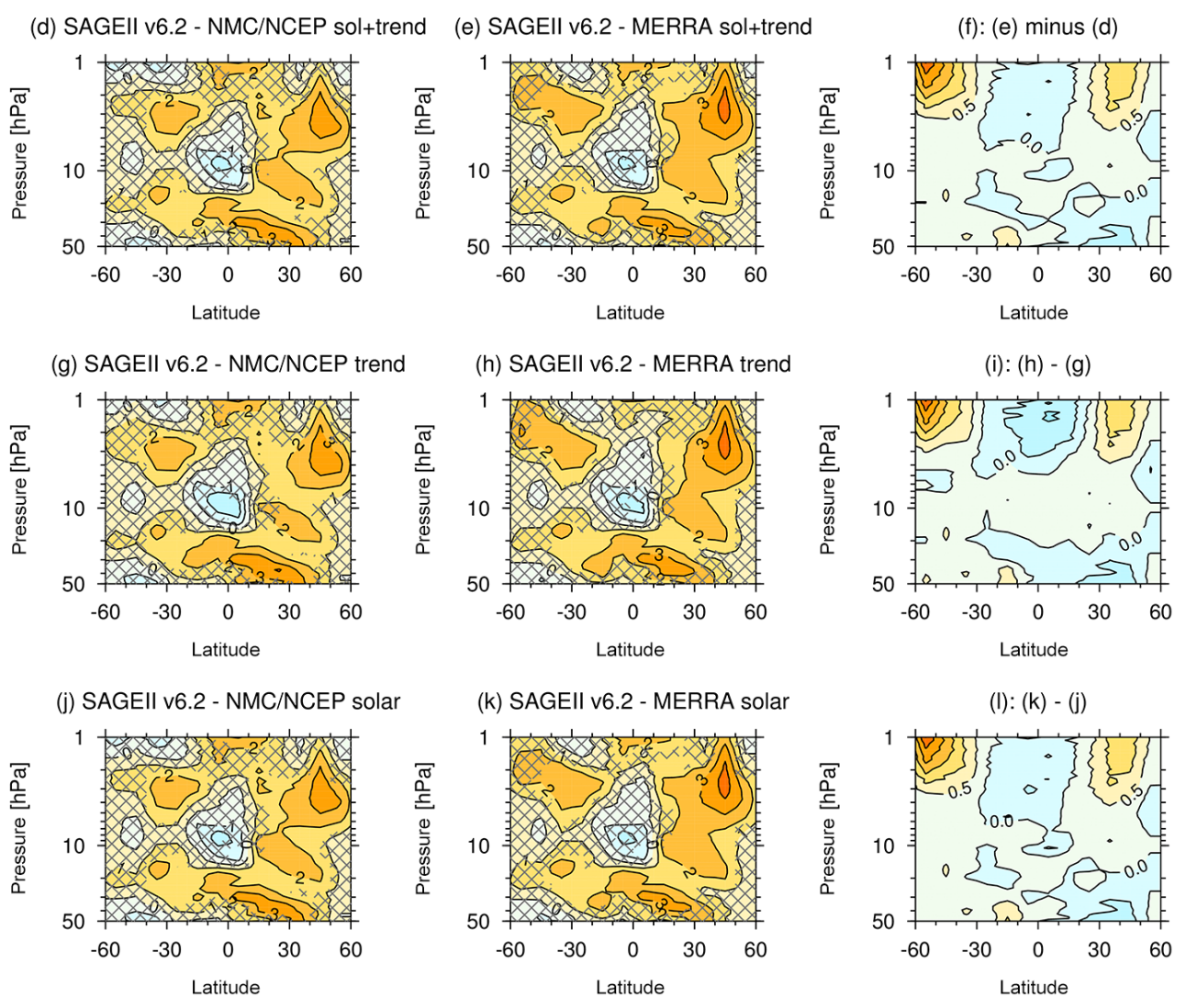

Figure 8. The percent (\%) annual solar-ozone response (SOR) (per 130 SFU) in SAGE II v6.2 data converted from number densities to mixing ratios for the period 1985-2003 using the method described in Sect. 4.1.2. The conversion is first conducted using full time series of monthly (a) NMC/NCEP and (b) MERRA-1 temperatures. Panel (c) shows (b) minus (a). A comparison of panels (a-c) with Fig. 4a-c demonstrates the performance of the post hoc conversion. (d-f) As in panels (a-c) but with the number density to mixing ratio conversion performed using a monthly temperature climatology from MERRA-1 added to a linear trend and solar signal in stratospheric temperatures extracted from (d) NMC/NCEP and (e) MERRA-1. The remaining rows show the same as panels (d-f) but with the conversion performed with the ( $\mathbf{g}-\mathbf{i})$ linear trend or $(\mathbf{j}-\mathbf{l})$ solar cycle temperature terms alone. The shading is as is Fig. 4 . The contour interval is $1 \%$ in the left and middle columns and $0.5 \%$ in the right-hand column.

ing the overlap period up to 2011. QBO-like variations in ozone are visible in the time series at 24 and $31 \mathrm{~km}$. At $36 \mathrm{~km}$, there is a decline in ozone from 2004 to 2009 in all three datasets, with increases subsequent to this. However, in the upper stratosphere $(48 \mathrm{~km})$, there are more substantial differences between the datasets, particularly between the SAGE-GOMOS $1 / 2$ and SAGE-OSIRIS records. SAGEOSIRIS shows mean positive anomalies from 2004 to 2013, particularly in the latter part of the record, whereas the two
SAGE-GOMOS datasets show negative anomalies between 2007-2010, which coincide with the minimum of solar cycle 23 . These differences in ozone variability during the postSAGE II period may affect the SORs diagnosed in the extended datasets, as compared to the SAGE II v7.0 data alone (Fig. 4b).

Figure 10a-c show the SORs in the three extended SAGE II datasets, and Fig. 10d-f show their associated $95 \%$ confidence intervals in terms of percent ozone. An indication 

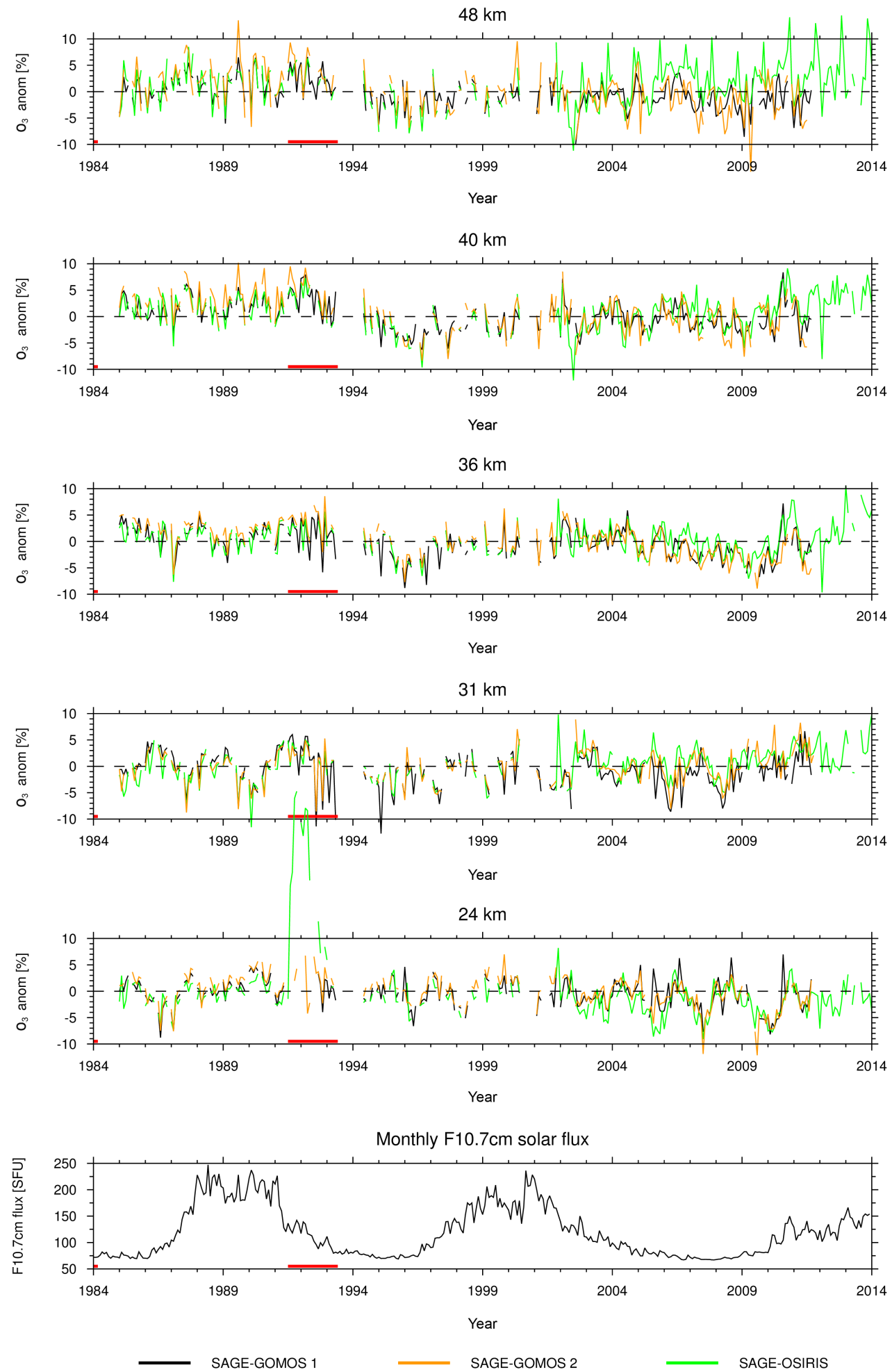

Figure 9. As in Fig. 3 but for the three extended SAGE II number density datasets: SAGE-GOMOS 1 (black), SAGE-GOMOS 2 (orange), and SAGE-OSIRIS (green). The time period is 1984-2013. 
(a) SAGE-GOMOS 1: 1984-2011

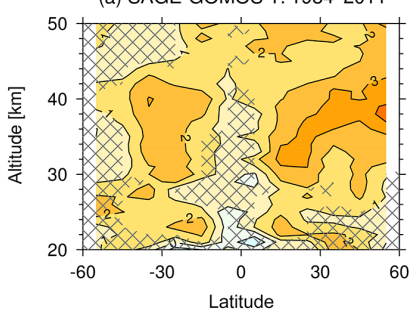

(d) SAGE-GOMOS 1: 1984-2011

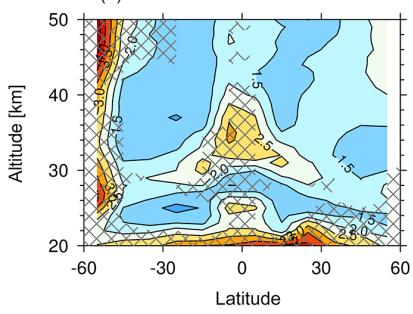

$\mathrm{O}_{3}[\%] \mathrm{S}_{\max }-\mathrm{S}_{\min }$

(b) SAGE-GOMOS 2: 1984-2011

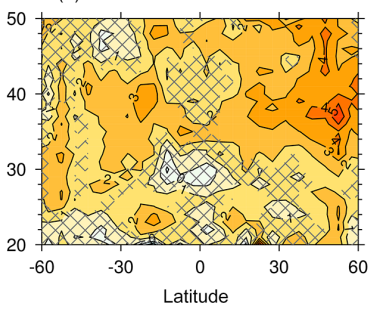

$\mathrm{O}_{3}[\%] \mathrm{S}_{\max }-\mathrm{S}_{\min }$ uncertainty

(e) SAGE-GOMOS 2: 1984-2011

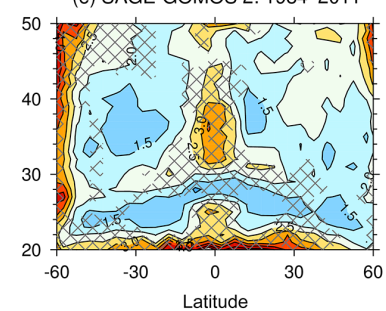

(c) SAGE-OSIRIS: 1984-2013

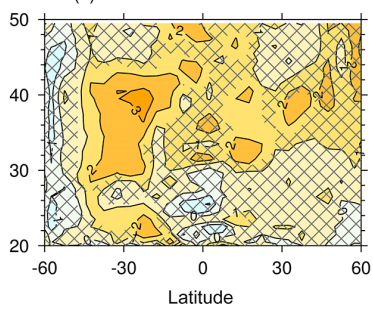

(f) SAGE-OSIRIS: 1984-2013

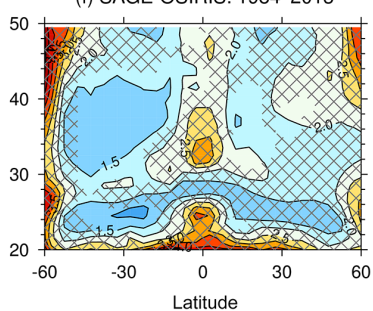

Figure 10. (a-c) As in Fig. 4 but for the extended SAGE II number density datasets: (a) SAGE-GOMOS 1, (b) SAGE-GOMOS 2, and (c) SAGE-OSIRIS. SORs are derived for different periods as stated in the headers. The contour interval is $1 \%$. (d-f) As in Fig. 5 but for the datasets as shown in panels (a-c). The contour interval is $0.5 \%$. The hatching is as in Fig. 4.

of the importance of how the satellite records are merged for the SOR can be seen by comparing Fig. 10a and b, which show SAGE-GOMOS 1 and SAGE-GOMOS 2, respectively. The SOR in SAGE-GOMOS 1 shows a generally smoother spatial structure as compared to SAGE-GOMOS 2, although the magnitudes are not distinguishable from one another given the estimated confidence intervals (Fig. 10de). Nevertheless, since statistical uncertainties in the SOR are not typically accounted for in solar-climate studies (e.g. Gray et al., 2009) or in climate model ozone datasets (e.g. Cionni et al., 2011), differences in the best estimate of the SOR between the datasets remain important to characterize. The differences in SOR between SAGE-GOMOS 1 and 2 must arise from differences in the data merging procedures, which are summarized by Tummon et al. (2015) and are described in detail by Kyrölä et al. (2013) and Penckwitt et al. (2015). Analysis of the SOR in the two SAGE-GOMOS datasets over the SAGE II period alone (1984-2004) reveals similar differences in magnitude and structure (not shown), which suggests that the use of SAGE II or GOMOS as a reference to which the other record is adjusted is a key factor for the differences in SOR in Fig. 10a and b. The uncertainties in the SOR in SAGE-GOMOS 2 (Fig. 10e) are similar to those found in the SAGE II v7.0 number density dataset (Fig. 5b), whereas the magnitude of the uncertainties in the SOR in SAGE-GOMOS 1 (Fig. 10d) are reduced compared to SAGE II v7.0, particularly in the upper stratosphere.

The SOR in the SAGE-OSIRIS dataset (Fig. 10c) shows significant positive values in the subtropics between $\sim 30$ and
$40 \mathrm{~km}$. This is consistent with the results of Bourassa et al. (2014) who conducted a similar MLR analysis to assess longterm ozone trends in SAGE-OSIRIS (see also Tummon et al., 2015). However, the SOR is smaller and less significant in the tropical upper stratosphere and northern extratropics as compared to the two SAGE-GOMOS datasets and the SAGE II v7.0 data. Hubert et al. (2016) identified a significant positive drift of $5-8 \%$ decade $^{-1}$ in OSIRIS data above $35 \mathrm{~km}$ compared to ozonesondes and lidar measurements, which may contribute to the differences in SOR in the upper stratosphere.

Although there are broad similarities in the SOR between the three extended SAGE II datasets there are also important differences. This is despite the fact that all of the datasets use SAGE II v7.0 number densities as a basis. There is therefore a trade-off between generating the longest climate data record possible, which is desirable for analysing quasidecadal signals, and the introduction of additional sources of uncertainty from combining multiple satellite records with different sampling properties and drifts (Harris et al., 2015). There appear to be variations in ozone in the OSIRIS record that reduce the magnitude of the SOR in the extended SAGEOSIRIS record compared to the SAGE II period alone. When the SAGE-GOMOS datasets are analysed over the SAGE II period (1984-2004; not shown), SAGE-GOMOS 1 shows the greatest resemblance to the original SAGE II v7.0 data in Fig. $4 \mathrm{~b}$ and is characterized by the smallest uncertainties of the three datasets in the upper stratosphere, and we therefore 
conclude that this record is likely the most reliable estimate of the SOR from the extended SAGE II datasets considered.

\subsection{The SOR in SBUV records}

Figure 11 shows time series of tropical monthly percent ozone anomalies at select stratospheric levels (as in Fig. 3) for the SBUVMOD VN8.0 (black line), SBUVMOD VN8.6 (red line), and SBUV Merged Cohesive VN8.6 (blue line) datasets. At $1 \mathrm{hPa}$, the ozone anomalies in the different SBUV datasets are in good agreement between 1979 and 1994. After 1994, the main differences are found between the SBUVMOD VN8.0 and the two SBUV VN8.6 datasets, the latter being largely consistent with one another. In particular, SBUVMOD VN8.0 shows a larger positive trend in ozone from the mid-1990s to the mid-2000s than in the SBUV VN8.6 records; this partly coincides with the ascending phase of solar cycle 23 . At $3 \mathrm{hPa}$, a comparison of the three SBUV records reveals somewhat different behaviour. Here, the SBUVMOD VN8.0 and SBUV Merged Cohesive VN8.6 datasets show similar ozone variations, and instead the SBUVMOD VN8.6 is an outlier exhibiting a larger decline in ozone compared to the other two records of $\sim 7-$ $8 \%$ over the period 1979-2012. At $5 \mathrm{hPa}$, the three SBUV datasets generally show similar temporal variations in ozone in the early and latter parts of the records, with some differences in offsets linked to different behaviours in the late 1990s and early 2000s when data come from the NOAA-11, 14, 16, and 17 satellites. At $30 \mathrm{hPa}$, the three SBUV records are largely consistent with one another in their short- and long-term variations, with some exceptions during the 1990s when the data come mainly from the NOAA-11 and NOAA14 satellites (see, e.g., Tummon et al., 2015).

Figure 12a, b, and $c$ show the annual mean SORs in the SBUVMOD VN8.0, SBUVMOD VN8.6, and SBUV Merged Cohesive VN8.6 datasets, respectively. Figure 12d$\mathrm{f}$ show the associated $95 \%$ confidence intervals in terms of percent ozone. All three SBUV records show a significant positive SOR in some parts of the upper stratosphere of up to $2-3 \%$. The SOR in the tropical upper stratosphere is smaller and not highly statistically significant in SBUVMOD VN8.6, which is in contrast to the two other records and somewhat resembles the SOR in SAGE II v7.0 mixing ratios (Fig. 4e). The modifications to the data processing algorithm between SBUVMOD VN8.0 and SBUVMOD VN8.6 are documented by Bhartia et al. (2013); these include the use of new ozone absorption cross sections, a new a priori ozone climatology, and a new cloud-height climatology. In addition, changes were also made to the inter-instrument calibration, which is now achieved at the radiance level during periods of overlap between the SBUV instruments (DeLand et al., 2012; Bhartia et al., 2013). Note that the difference in SOR in the tropical upper stratosphere between the two SBUV VN8.6 records remains when SBUVMOD VN8.6 is analysed over the shorter 1978-2012 period (not shown), so this does not result from the inclusion of the early BUV measurements in SBUVMOD VN8.6.

The SORs in the three SBUV records show further differences between $10-50 \mathrm{hPa}$, with SBUVMOD VN8.6 showing a larger and more significant SOR, particularly in the northern extratropics, while SBUV Merged Cohesive VN8.6 shows a weaker SOR. However, we note that the poor vertical resolution $(\sim 10 \mathrm{~km})$ of the SBUV instruments at pressures greater than $\sim 15 \mathrm{hPa}$ makes it challenging to resolve features in the mid and lower stratosphere. Note that the confidence intervals for all the SBUV records are smaller than those for SAGE II-based records (see Figs. 5 and 10d-f). This is likely to be because the number of data points included in the MLR analysis is around 2-3 times higher for the SBUV datasets than for the SAGE II records (see Figs. S1 and S3 in the Supplement).

It is desirable for the purposes of, e.g., chemistry-climate model evaluation to determine which SBUV dataset might be most reliable for estimating the annual mean SOR. Lean (2014) analysed total column ozone measurements from SBUVMOD VN8.0 and SBUVMOD VN8.6 and found a smaller SOR in SBUVMOD VN8.6 near-global column ozone, which appeared to be related to instrument effects around the 1996 time frame. However, Hood (1997) analysed the SOR in total column ozone data and found that most of the signal is associated with ozone changes in the lower stratosphere that are linked to dynamical processes. Column ozone measurements are therefore unlikely to be particularly helpful for constraining the SOR in the upper stratosphere, where differences are found amongst many of the datasets analysed here and where the SOR is strongly determined by photochemical processes.

Tummon et al. (2015) analysed vertical profiles of longterm ozone trends in satellite datasets and found that SBUV Merged Cohesive VN8.6 showed negligible ozone trends at $2 \mathrm{hPa}$ over 1984-1997, whereas almost all other datasets analysed, including SBUVMOD VN8.6, showed a significant decline of several percent per decade over this period. Instead, SBUV Merged Cohesive VN8.6 showed larger negative ozone trends that the other datasets between $5-10 \mathrm{hPa}$. Wild and Long (2015) and Tummon et al. (2015) explain how the adjustments used to combine data from the ascending node of NOAA-11 with NOAA-9 and NOAA-14 in SBUV Merged Cohesive VN8.6 were determined from the overlap of the descending node of NOAA- 11 with NOAA- 16 because of known issues with the quality of data from NOAA-9 and NOAA-14 (Kramavora et al., 2013). Since the NOAA-9 and NOAA-14 data coincide with the end of the trend analysis period used by Tummon et al. (2015), this could have had a particularly pronounced impact on their linear trend calculations but may not be as important for diagnosing the SOR.

From the time series of $1 \mathrm{hPa}$ ozone anomalies shown in Fig. 11, it would appear that differences between the two SBUV VN8.6 datasets in the early 2000s may be more important for determining the differences in SOR in the 

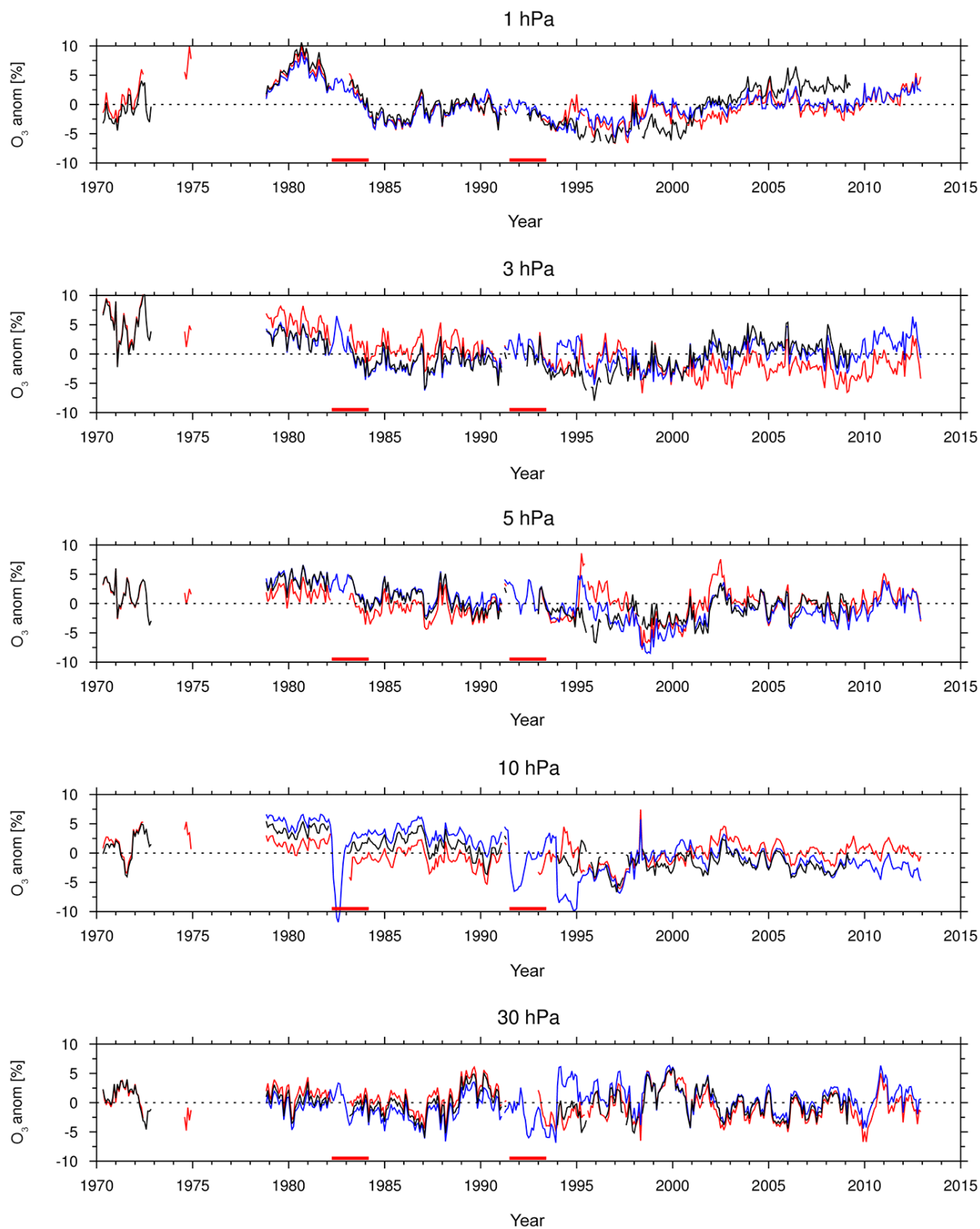

F10.7 cm solar flux

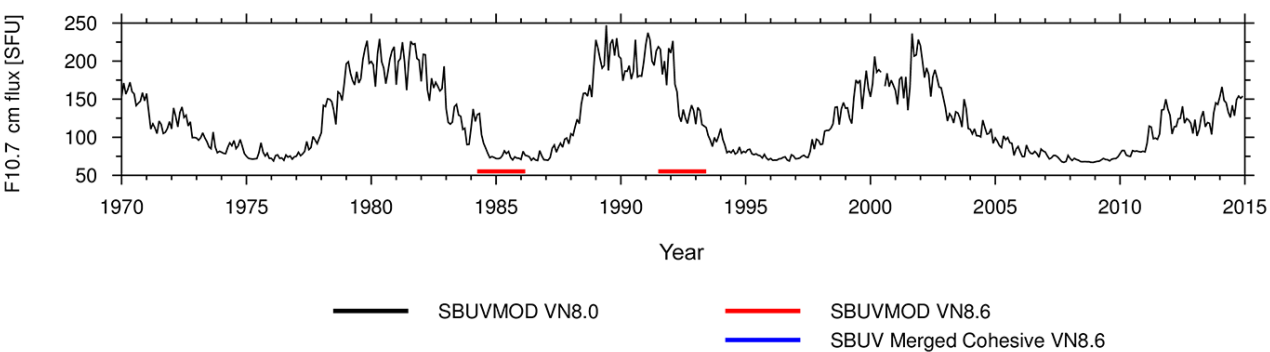

Figure 11. As in Fig. 3 but for the SBUVMOD VN8.0 (black), SBUVMOD VN8.6 (red), and SBUV Merged Cohesive VN8.6 (blue) datasets. The time period is 1970-2014. 

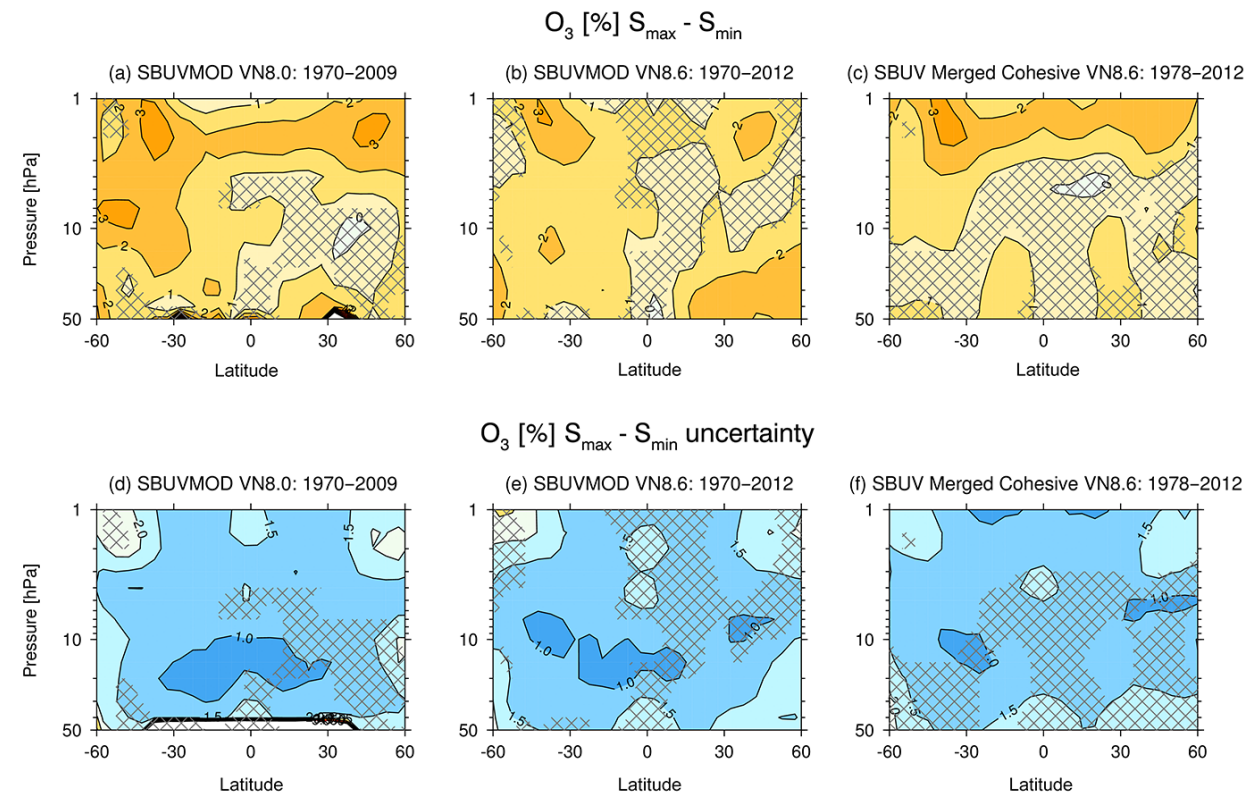

Figure 12. As in Fig. 10 for the (a, d) SBUVMOD VN8.0, (b, e) SBUVMOD VN8.6, and (c, f) SBUV Merged Cohesive VN8.6 datasets. SORs are derived for different periods as stated in the headers. The contour interval in panels (a-c) is $1 \%$ and $0.5 \%$ in panels (d-f).

tropical upper stratosphere. During this period, which coincides with the maximum of solar cycle 22, SBUVMOD VN8.6 shows persistently more negative ozone anomalies than SBUV Merged Cohesive VN8.6. Further analysis of the SOR for the period up to the year 2000 (not shown) does produce a slightly larger and more significant SOR in the tropical upper stratosphere in SBUVMOD VN8.6, but the magnitude is still $\sim 1 \%$ smaller than in SBUV Merged Cohesive VN8.6, indicating that the post-2000 period alone does not explain all differences between Fig. 12b and c. Based on the above factors, it is difficult to assert which of the SBUV VN8.6 datasets is likely to be most reliable for estimating the SOR. However, in practice the differences between the SORs in the tropical upper stratosphere in the SBUV records are small compared to their associated statistical uncertainties (Fig. 12d-f) and small compared to the differences in SOR between the two SAGE II mixing ratio datasets in this region. We therefore conclude that using the longest climate data record is most favourable for diagnosing the SOR, particularly on seasonal timescales (see Sect. 4.4), and we therefore adopt SBUVMOD VN8.6 for this purpose.

\subsection{Seasonality in the solar-ozone response}

The analysis thus far has described the annual mean SOR in satellite ozone datasets. However, the SOR is expected to exhibit a seasonal dependence; for example, in regions close to photochemical steady state the annual cycle in solar zenith angle would be expected to produce a larger SOR in the summer hemisphere (Haigh, 1994). Furthermore, given the hypothesis that solar variability modifies the strength of the stratospheric polar vortex (Kuroda and Kodera, 2002), there may also be seasonal signatures in the SOR arising from changes in ozone transport, particularly in the winter hemispheres. Seasonal variations in the SOR could potentially influence the climate response to solar forcing through coupling to radiation (e.g. Hood et al., 2015), and it is therefore important to characterize these in observations and chemistry-climate models.

Constraining the SOR on seasonal timescales requires high spatial and temporal data coverage; this is to ensure that any seasonal component of the signal can be resolved but also to increase the number of degrees of freedom (i.e. the number of data points) available for the regression. Such coverage is not adequately provided by limb-viewing instruments, such as SAGE II, which have relatively sparse and infrequent sampling. The coverage is considerably better for nadir-viewing instruments like SBUV; however, as described above, their vertical resolution is much poorer in the middle and lower stratosphere. There is therefore a trade-off between the information about the SOR that can be usefully extracted from different data sources.

Given the denser sampling of SBUV compared to SAGE II, we focus here on the SBUVMOD VN8.6 dataset to examine the seasonality of the SOR. Figure 13 shows the monthly SOR in SBUVMOD VN8.6 for the period 19702012. These values are calculated by applying the MLR model to time series for individual months, and therefore no autocorrelation term has been included, since separate months are approximately uncorrelated from year to year. We note that the detailed magnitudes and structure of the monthly SORs are more sensitive to the choice of analysis 
SBUVMOD VN8.6 1970-2012
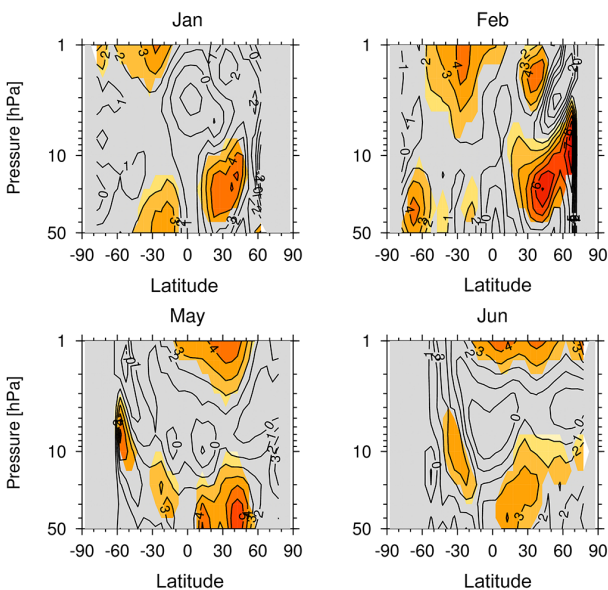

Sep

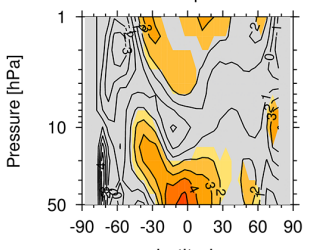

Latitude
Jun

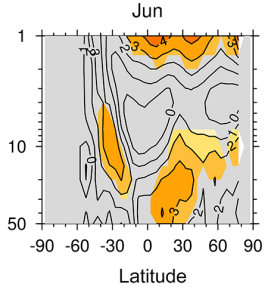

Oct

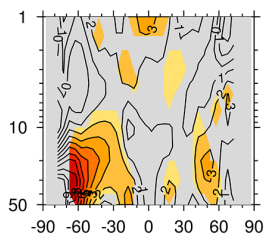

Latitude
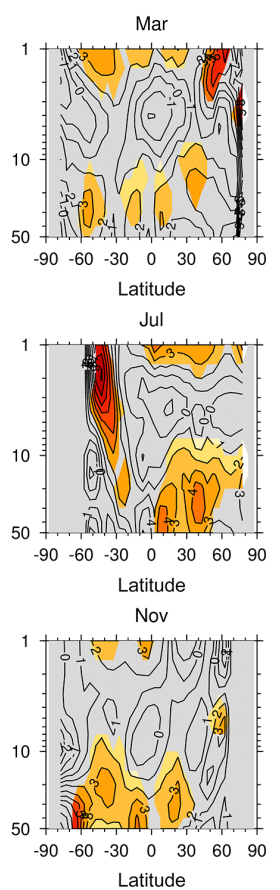

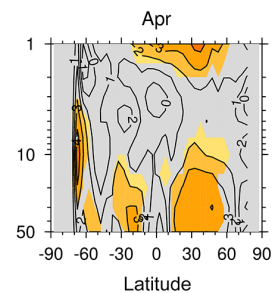

Aug
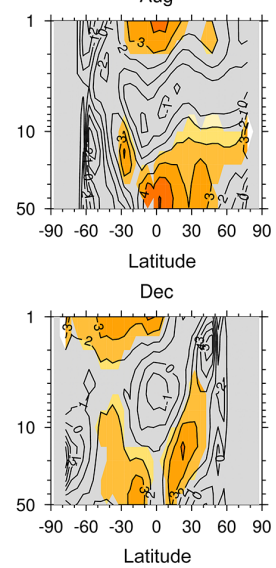

Figure 13. The percent (\%) monthly solar-ozone response (SOR) (per 130 SFU) in the SBUVMOD VN8.6 dataset for the period 1970-2012. The contour interval is $1 \%$. The grey shading denotes regions where the SOR is not statistically distinguishable from 0 at the $95 \%$ confidence level.

epoch than for the annual mean SOR (not shown), but the broad features generally remain consistent. The key point to take from Fig. 13 is that there are substantially enhanced meridional and vertical gradients in the monthly SORs as compared to the annual mean SOR for SBUVMOD VN8.6 in Fig. 12b. This is similar to the conclusion reached by Hood et al. (2015).

Although much of the localized variations in the SOR are driven by dynamical processes, it is also possible that they could feedback onto circulation through the radiative impacts of ozone on stratospheric heating rates and temperatures. Hood et al. (2015) concluded that the three chemistryclimate models from CMIP5 that simulate strong gradients in ozone in the winter upper stratosphere, which most closely resemble observations, tend to have high-latitude dynamical responses to the solar cycle that are most similar to reanalysis data. Seasonal variations in the SOR may therefore play a role in the ability of a model to simulate the climate response to solar variability. However, given the tight coupling between ozone and dynamics at higher latitudes, the attribution of the importance of such radiative feedbacks is particularly challenging. To our knowledge, the importance of this two-way coupling for the climate response to solar variability has not been explicitly tested. This is important to clarify because it is not known whether it is sufficient to simply prescribe a seasonally varying SOR or whether a fully interactive chemistry-climate model is required to adequately capture the feedbacks between composition, radiation, and dynamics that lead to an amplified regional response to the solar cycle. The representation of the SOR in global climate models is discussed in more detail in Part 2 of this study (Maycock et al., 2016).

\section{Conclusions}

The solar-ozone response (SOR) forms an important part of the climate response to 11-year solar cycle variability through its impact on stratospheric temperatures (e.g. Shibata and Kodera, 2005; Gray et al., 2009). This papers forms the first of a two-part study that aims to quantify the SOR in current satellite observations and chemistry-climate models. Part 1 has focused on comparing the SOR in recently updated and/or extended versions of long-term satellite ozone datasets (e.g. SAGE II, SBUV) with their previous counterparts (e.g. Soukharev and Hood, 2006; Austin et al., 2008).

The SAGE II dataset has been widely used for ozone studies because of its long-term stability. SAGE II ozone data are available as number densities on altitude levels and postprocessed to mixing ratios on pressure levels. The SAGE II version 6.2 (v6.2) mixing ratio dataset shows a positive annual mean SOR with a peak magnitude of $\sim 5 \%$ near the tropical stratopause. However, the more recent SAGE II v7.0 dataset shows a substantially smaller SOR at the tropical 
stratopause of $\sim 1 \%$. Conversely, the SORs in the equivalent SAGE II number density datasets are much more consistent for v6.2 and v7.0 and show a three-peaked structure in the tropics and subtropics with a magnitude of up to $3-4 \%$.

By applying a post hoc method to convert SAGE II number densities to mixing ratios, we have shown that the differences in SOR are strongly determined by the change in independent temperature record used to convert SAGE II number densities to mixing ratios: v6.2 uses NMC/NCEP and v7.0 uses MERRA-1 temperatures. Differences between these temperature records in both long-term trends and solar cycle variations contribute to the changes in SOR described above. Since both temperature records contain known issues (e.g. Damadeo et al., 2013; Mitchell et al., 2015a), we conclude that the latest SAGE II v7.0 ozone number densities are likely to be most reliable for estimating the SOR at the present time. This is an important conclusion because several of the existing ozone datasets developed for use in global climate models have been based on SAGE II v6.2 mixing ratio data, including the dataset developed for CMIP5 simulations (Cionni et al., 2011).

We further analysed the annual mean SOR in three extended SAGE II datasets that have merged more recent GOMOS (2002-2011) or OSIRIS (2002-2013) data with SAGE II v7.0 number densities. Two SAGE-GOMOS datasets were analysed that adopt different methods for merging the satellite records (Kyrölä et al., 2013; Penckwitt et al., 2015). These records show broadly similar SORs, but the dataset that uses SAGE II as a reference and adjusts GOMOS using seasonally varying offsets at each latitude and altitude (Penckwitt et al., 2015) was found to have a SOR with a noisier spatial structure. The SAGE-OSIRIS dataset (Bourassa et al., 2014) shows a significant positive SOR of $\sim 2 \%$ between 30 and $40 \mathrm{~km}$ but a weaker and less significant SOR in the tropical upper stratosphere than is found in the SAGE-GOMOS datasets. Thus, the inclusion of OSIRIS data results in a markedly different SOR to that found in the SAGE II v7.0 number densities that underpin the first part of the record. Given these various issues, we conclude that the SAGE-GOMOS 1 dataset (Kyrölä et al., 2013) is likely to be the most reliable extended SAGE II dataset for estimating the SOR at the present time.

Analysis of the recently released SBUVMOD VN8.6 data produced by NASA show a SOR in the tropical upper stratosphere that is smaller by $\sim 1 \%$ compared to the previous SBUVMOD VN8.0 data (Soukharev and Hood, 2006). However, the SBUV Merged Cohesive VN8.6 dataset from NOAA, which takes a different approach for combining the individual SBUV VN8.6 records, shows a SOR that more closely matches SBUVMOD VN8.0. Nevertheless, the differences in the magnitude of the SOR between the various SBUV records are generally smaller than those between the SAGE II v6.2 and v7.0 mixing ratio datasets and are not highly statistically significant given the estimated uncertainties in the SOR derived from the regression model. We there- fore suggest that the SBUVMOD VN8.6 dataset is most appropriate for analysing the SOR since it is the longest of the currently available SBUV VN8.6 records (1970-2012).

Analysis of the SOR on monthly timescales in the SBUVMOD VN8.6 dataset reveals substantially larger horizontal and vertical gradients in the SOR, particularly in the winter extratropics. Hood et al. (2015) analysed CMIP5 models with interactive chemistry and concluded that the models with seasonal variations in the SOR that best matched observations simulated changes in high-latitude zonal winds over the solar cycle that more closely resemble reanalysis data. Seasonal variations in the SOR may therefore be important for the climate response to solar variability, but the quantitative importance of this feedback for stratospheric dynamics remains to be tested.

To allow for a realistic representation of the climate impacts of solar variability in models, simulations should include the effects of both the SOR and variations in spectral solar irradiance (Matthes et al., 2016). Our results raise issues for how to best represent the SOR in "non-interactive" climate models for which the SOR much be externally prescribed. For example, ozone databases for climate models are usually created using a variety of ozone measurements, and therefore implicitly include a representation of the SOR that emerges from whichever combinations of data are included (e.g. Cionni et al., 2011; Bodeker et al., 2013). However, the differences in the magnitude and structure of the SOR between various satellite datasets as described here would likely result in different climate responses to solar forcing. There is therefore a need for new studies to explore the effects of uncertainties in the SOR for climate simulation, particularly in light of the substantial, but largely unexplained, spread in climate responses to the 11-year solar cycle across CMIP5 models (Mitchell et al., 2015b; Hood et al., 2015).

\section{Data availability}

The SAGE II and SBUVMOD datasets used in this study are all publicly available online. Citations or links to data sources have been included wherever possible. The $\mathrm{SI}^{2} \mathrm{~N}$ ozone datasets were kindly provided by Fiona Tummon. Users wishing to access the $\mathrm{SI}^{2} \mathrm{~N}$ datasets should contact the Principal Investigators directly.

\section{The Supplement related to this article is available online at doi:10.5194/acp-16-10021-2016-supplement.}

Acknowledgements. Amanda C. Maycock acknowledges funding from an AXA Postdoctoral Fellowship, the ERC ACCI Grant Project No. 267760, and a NERC Independent Research Fellowship (NE/M018199/1). Amanda C. Maycock also acknowledges 
funding from the COST action ES1005 "Towards a more complete assessment of the impact of solar variability on the Earth's climate" (TOSCA) for a Short-term Scientific Mission to GEOMAR in September 2014 which initiated this work. Parts of the work at GEOMAR Helmholtz Centre for Ocean Research Kiel was performed within the Helmholtz University Young Investigators Group NATHAN, funded by the Helmholtz Association and GEOMAR. We thank Fiona Tummon for kindly providing the merged ozone datasets that formed part of the $\mathrm{SI}^{2} \mathrm{~N}$ initiative. We thank Stacey Frith for providing useful information about the SBUV records. We also thank the many instrument scientists and groups who have contributed to the development of long-term satellite ozone datasets and who have kindly made their data available for this study. The authors thank J. Zawodny, J. Lean, and the two anonymous reviewers for their detailed review comments, which improved the manuscript.

Edited by: M. Dameris

Reviewed by: J. Zawodny, J. Lean, and two anonymous referees

\section{References}

Austin, J., Tourpali, K., Rozanov, E., Akiyoshi, H., Bekki, S., Bodeker, G., Brühl, C., Butchart, N., Chipperfield, M., Deushi, M., Fomichev, V. I., Giorgetta, M. A., Gray, L., Kodera, K., Lott, F., Manzini, E., Marsh, D., Matthes, K., Nagashima, T., Shibata, K., Stolarski, R. S., Struthers, H., and Tian, W.: Coupled chemistry climate model simulations of the solar cycle in ozone and temperature, J. Geophys. Res., 113, D11306, doi:10.1029/2007JD009391, 2008.

Ball, W. T., Haigh, J. D., Rozanov, E. V., Kuchar, A., Sukhodolov, T., Tummon, F., Shapiro, A. V., and Schmutz, W.: High solar cycle spectral variations inconsistent with stratospheric ozone observations, Nat. Geosci., 9, 206-209, 2016.

Bhartia, P. K., McPeters, R. D., Flynn, L. E., Taylor, S., Kramarova, N. A., Frith, S., Fisher, B., and DeLand, M.: Solar Backscatter UV (SBUV) total ozone and profile algorithm, Atmos. Meas. Tech., 6, 2533-2548, doi:10.5194/amt-6-2533-2013, 2013.

Bodeker, G. E., Hassler, B., Young, P. J., and Portmann, R. W.: A vertically resolved, global, gap-free ozone database for assessing or constraining global climate model simulations, Earth Syst. Sci. Data, 5, 31-43, doi:10.5194/essd-5-31-2013, 2013.

Bourassa, A. E., Degenstein, D. A., Randel, W. J., Zawodny, J. M., Kyrölä, E., McLinden, C. A., Sioris, C. E., and Roth, C. Z.: Trends in stratospheric ozone derived from merged SAGE II and Odin-OSIRIS satellite observations, Atmos. Chem. Phys., 14, 6983-6994, doi:10.5194/acp-14-6983-2014, 2014.

Chiodo, G., Marsh, D. R., Garcia-Herrera, R., Calvo, N., and García, J. A.: On the detection of the solar signal in the tropical stratosphere, Atmos. Chem. Phys., 14, 5251-5269, doi:10.5194/acp-14-5251-2014, 2014.

Cionni, I., Eyring, V., Lamarque, J. F., Randel, W. J., Stevenson, D. S., Wu, F., Bodeker, G. E., Shepherd, T. G., Shindell, D. T., and Waugh, D. W.: Ozone database in support of CMIP5 simulations: results and corresponding radiative forcing, Atmos. Chem. Phys., 11, 11267-11292, doi:10.5194/acp-11-11267-2011, 2011.

Damadeo, R. P., Zawodny, J. M., Thomason, L. W., and Iyer, N.: SAGE version 7.0 algorithm: application to SAGE II, At- mos. Meas. Tech., 6, 3539-3561, doi:10.5194/amt-6-3539-2013, 2013.

Davis, S. M., Rosenlof, K. H., Hassler, B., Hurst, D. F., Read, W. G., Vömel, H., Selkirk, H., Fujiwara, M., and Damadeo, R.: The Stratospheric Water and Ozone Satellite Homogenized (SWOOSH) database: A long-term database for climate studies, Earth Syst. Sci. Data Discuss., doi:10.5194/essd-2016-16, in review, 2016.

DeLand, M. T., Taylor, S. L., Huang, L. K., and Fisher, B. L.: Calibration of the SBUV version 8.6 ozone data product, Atmos. Meas. Tech., 5, 2951-2967, doi:10.5194/amt-5-2951-2012, 2012.

Dhomse, S., Chipperfield, M. P., Feng, W., and Haigh, J. D.: Solar response in tropical stratospheric ozone: a 3-D chemical transport model study using ERA reanalyses, Atmos. Chem. Phys., 11, 12773-12786, doi:10.5194/acp-11-12773-2011, 2011.

Dhomse, S., Chipperfield, M. P., Damadeo, R. P., Zawodny, J. M., Ball, W., Feng, W., Hossaini, R., Mann, G. W., and Haigh, J. D.: On the ambiguous nature of the 11-year solar cycle signal profile in stratospheric ozone, Geophys. Res. Lett., 43, 7241-7249, doi:10.1002/2016GL069958, 2016.

Ermolli, I., Matthes, K., Dudok de Wit, T., Krivova, N. A., Tourpali, K., Weber, M., Unruh, Y. C., Gray, L., Langematz, U., Pilewskie, P., Rozanov, E., Schmutz, W., Shapiro, A., Solanki, S. K., and Woods, T. N.: Recent variability of the solar spectral irradiance and its impact on climate modelling, Atmos. Chem. Phys., 13, 3945-3977, doi:10.5194/acp-13-3945-2013, 2013.

Frame, T. H. A. and Gray, L. J.: The 11-yr solar cycle in ERA-40 date: An update to 2008, J. Climate, 23, 2213-2222, 2010.

Frith, S. M., Kramarova, N. A., Stolarski, R. S., McPeters, R. D., Bhartia, P. K., and Labow, G. J.: Recent changes in column ozone based on the SBUV version 8.6 merged ozone database, J. Geophys. Res., 119, 9735-9751, 2014.

Froidevaux, L., Anderson, J., Wang, H.-J., Fuller, R. A., Schwartz, M. J., Santee, M. L., Livesey, N. J., Pumphrey, H. C., Bernath, P. F., Russell III, J. M., and McCormick, M. P.: Global OZone Chemistry And Related trace gas Data records for the Stratosphere (GOZCARDS): methodology and sample results with a focus on $\mathrm{HCl}, \mathrm{H}_{2} \mathrm{O}$, and $\mathrm{O}_{3}$, Atmos. Chem. Phys., 15, 1047110507, doi:10.5194/acp-15-10471-2015, 2015.

Gray, L. J., Rumbold, S., and Shine, K. P.: Stratospheric temperatures and radiative forcing response to 11-year solar cycle changes in irradiance and ozone, J. Atmos. Sci., 66, 2402-2417, 2009.

Gray, L. J., Beer, J., Geller, M., Haigh, J. D., Lockwood, M., Matthes, K., Cubasch, U., Fleitmann, D., Harrison, G., Hood, L., Luterbacher, J., Meehl, G. A., Shindell, D., van Geel, B., and White, W.: Solar influences on climate, Rev. Geophys., 48, RG4001, doi:10.1029/2009RG000282, 2010.

Haigh, J. D.: The role of stratospheric ozone in modulating the solar radiative forcing of climate, Nature, 370, 544-546, 1994.

Haigh, J. D., Winning, A. R., Toumi, R., and Harder, J. W.: An influence of solar spectral variations on radiative forcing of climate, Nature, 467, 696-699, 2010.

Harris, N. R. P., Hassler, B., Tummon, F., Bodeker, G. E., Hubert, D., Petropavlovskikh, I., Steinbrecht, W., Anderson, J., Bhartia, P. K., Boone, C. D., Bourassa, A., Davis, S. M., Degenstein, D., Delcloo, A., Frith, S. M., Froidevaux, L., Godin-Beekmann, S., Jones, N., Kurylo, M. J., Kyrölä, E., Laine, M., Leblanc, 
S. T., Lambert, J.-C., Liley, B., Mahieu, E., Maycock, A., de Mazière, M., Parrish, A., Querel, R., Rosenlof, K. H., Roth, C., Sioris, C., Staehelin, J., Stolarski, R. S., Stübi, R., Tamminen, J., Vigouroux, C., Walker, K. A., Wang, H. J., Wild, J., and Zawodny, J. M.: Past changes in the vertical distribution of ozone - Part 3: Analysis and interpretation of trends, Atmos. Chem. Phys., 15, 9965-9982, doi:10.5194/acp-15-9965-2015, 2015.

Hegglin, M. I., Plummer, D., and Morgenstern, O.: An ozone dataset for CMIP6, Geosci. Mod. Dev., in preparation, 2016.

Hood, L. L.: The solar cycle variation of total ozone: Dynamical forcing in the lower stratosphere, J. Geophys. Res., 102, 13551370, doi:10.1029/96JD00210, 1997.

Hood, L. L., Misios, S., Mitchell, D. M., Rozanov, E., Gray, L. J., Tourpali, K., Matthes, K., Schmidt, H., Chiodo, G., Thiéblemont, R., Shindell, D., and Krivolutsky, A.: Solar signals in cmip-5 simulations: The ozone response, Q. J. Roy. Meteor. Soc., 141, 2670-2689, doi:10.1002/qj.2553, 2015.

Hubert, D., Lambert, J.-C., Verhoelst, T., Granville, J., Keppens, A., Baray, J.-L., Bourassa, A. E., Cortesi, U., Degenstein, D. A., Froidevaux, L., Godin-Beekmann, S., Hoppel, K. W., Johnson, B. J., Kyrölä, E., Leblanc, T., Lichtenberg, G., Marchand, M., McElroy, C. T., Murtagh, D., Nakane, H., Portafaix, T., Querel, R., Russell III, J. M., Salvador, J., Smit, H. G. J., Stebel, K., Steinbrecht, W., Strawbridge, K. B., Stuibi, R., Swart, D. P. J., Taha, G., Tarasick, D. W., Thompson, A. M., Urban, J., van Gijsel, J. A. E., Van Malderen, R., von der Gathen, P., Walker, K. A., Wolfram, E., and Zawodny, J. M.: Ground-based assessment of the bias and long-term stability of 14 limb and occultation ozone profile data records, Atmos. Meas. Tech., 9, 2497-2534, doi:10.5194/amt-9-2497-2016, 2016.

Ineson, S., Scaife, A., Knight, J. R., Manners, J. C., Dunstone, N. J., Gray, L. J., and Haigh, J. D.: Solar forcing of winter climate variability in the Northern Hemisphere, Nat. Geosci., 4, 753-757, doi:10.1038/ngeo1282, 2011.

Ineson, S., Maycock, A. C., Gray, L. J., Scaife, A. A., Dunstone, N. J., Harder, J. W., Knight, J. R., Lockwood, M., Manners, J. C., and Wood, R. A.: Regional climate impacts of a possible future grand solar minimum, Nature Communications, 6, 7535, doi:10.1038/ncomms8535, 2015.

Kramarova, N. A., Frith, S. M., Bhartia, P. K., McPeters, R. D., Taylor, S. L., Fisher, B. L., Labow, G. J., and DeLand, M. T.: Validation of ozone monthly zonal mean profiles obtained from the version 8.6 Solar Backscatter Ultraviolet algorithm, Atmos. Chem. Phys., 13, 6887-6905, doi:10.5194/acp-13-6887-2013, 2013.

Kuroda, Y. and Kodera, K.: Effect of solar activity on the Polarnight Jet Oscillation in the Northern and Southern hemisphere winter, J. Meteorol. Soc. Jpn., 80, 973-984, 2002.

Kyrölä, E., Laine, M., Sofieva, V., Tamminen, J., Päivärinta, S.M., Tukiainen, S., Zawodny, J., and Thomason, L.: Combined SAGE II-GOMOS ozone profile data set for 1984-2011 and trend analysis of the vertical distribution of ozone, Atmos. Chem. Phys., 13, 10645-10658, doi:10.5194/acp-13-10645-2013, 2013.

Lean, J.: Evolution of the Sun's Spectral Irradiance Since the Maunder Minimum, Geophys. Res. Lett., 27, 2425-2428, 2000.

Lean, J.: Evolution of Total Atmospheric Ozone from 1900 to 2100 Estimated with Statistical Models, J. Atmos. Sci., 71, 19561984, 2014.

Matthes, K., Langematz, U., Gray, L. J., Kodera, K., and Labitzke, K.: Improved 11-year solar signal in the Freie Universität Berlin
Climate Middle Atmosphere Model (FUB-CMAM), J. Geophys. Res., 109, D06101, doi:10.1029/2003JD004012, 2004.

Matthes, K., Kuroda, Y., Kodera, K., and Langematz, U.: Transfer of the solar signal from the stratosphere to the troposphere: Northern winter, J. Geophys. Res., 111, D06108, doi:10.1029/2005JD006283, 2006.

Matthes, K., Funke, B., Anderson, M. E., Barnard, L., Beer, J., Charbonneau, P., Clilverd, M. A., Dudok de Wit, T., Haberreiter, M., Hendry, A., Jackman, C. H., Kretschmar, M., Kruschke, T., Kunze, M., Langematz, U., Marsh, D. R., Maycock, A., Misios, S., Rodger, C. J., Scaife, A. A., Seppälä, A., Shangguan, M., Sinnhuber, M., Tourpali, K., Usoskin, I., van de Kamp, M., Verronen, P. T., and Versick, S.: Solar Forcing for CMIP6 (v3.1), Geosci. Model Dev. Discuss., doi:10.5194/gmd-2016-91, in review, 2016.

Maycock, A. C., Matthes, K., Tegtmeier, S., Thiéblemont, R., and Hood, L. L.: Solar cycle signals in stratospheric ozone - Part 2: Analysis of Climate Models, Atmos. Chem. Phys., in preparation, 2016.

McPeters, R. D., Miles, T., Flynn, L. E., Wellemeyer, C. G., and Zawodny, J. M.: Comparison of SBUV and SAGE II ozone profiles: Implications for ozone trends, J. Geophys. Res., 99, 2051320524, 1994.

McPeters, R. D., Bhartia, P. K., Haffner, D., Labow, G. J., and Flynn, L.: The version 8.6 SBUV ozone data record: An overview, J. Geophys. Res., 1168, 8032-8039, 2013.

Mitchell, D. M., Gray, L. J., Fujiwara, M., Hibino, T., Anstey, J., Harada, Y., Long, C., Misios, S., Stott, P. A., and Tan, D.: Signatures of natural variability in the atmosphere using multiple reanalysis datasets, Q. J. Roy. Meteor. Soc., 141, 2011-2031, doi:10.1002/qj.2492, 2015a.

Mitchell, D. M., Misios, S., Gray, L. J., Tourpali, K., Matthes, K., Hood, L. L., Schmidt, H., Chiodo, G., Thiéblemont, R., Rozanov, E., Shindell, D., and Krivolutsky, A.: Solar signals in cmip-5 simulations: the stratospheric pathway, Q. J. Roy. Meteor. Soc., 141, 2390-2403, doi:10.1002/qj.2530, 2015b.

Penckwitt, A. A., Bodeker, G. E., Revell, L. E., Richter, L., Kyrölä, E., and Young, P.: Construction and analysis of a new merged SAGE II-GOMOS ozone profile data set for 1984-2012, Earth Syst. Sci. Data, in preparation, 2015.

Ramaswamy, V., Chanin, M.-L., Angell, J., Barnett, J., Gaffen, D., Gelman, M., Keckhut, P., Koshelkov, Y., Labitzke, K., Lin, J.-J. R., O’Neill, A., Nash, J., Randel, W., Rood, R., Shine, K., Shiotani, M., and Swinbank, R.: Stratospheric temperature trends: Observations and model simulations, Rev. Geophys., 39, 71-122, 2001.

Randel, W. J. and Wu, F.: A stratospheric ozone profile data set for 1979-2005: Variability, trends, and comparisons with column ozone data, J. Geophys. Res., 112, D06313, doi:10.1029/2006JD007339, 2007.

Randel, W. J., Shine, K. P., Austin, J., Barnett, J., Claud, C., Gillett, N. P., Keckhut, P., Langematz, U., Lin, R., Long, C., Mears, C., Miller, A., Nash, J., Seidel, D. J., Thompson, D. W. J., Wu, F., and Yoden, S.: An update of observed stratospheric temperature trends, J. Geophys. Res., 114, D010421, doi:10.1029/2008JD010421, 2009.

Remsberg, E. and Lingenfelser, G.: Analysis of SAGE II ozone of the middle and upper stratosphere for its response to a 
decadal-scale forcing, Atmos. Chem. Phys., 10, 11779-11790, doi:10.5194/acp-10-11779-2010, 2010.

Remsberg, E. E.: Decadal-scale responses in middle and upper stratospheric ozone from SAGE II version 7 data, Atmos. Chem. Phys., 14, 1039-1053, doi:10.5194/acp-14-1039-2014, 2014.

Shibata, K. and Kodera, K.: Simulation of radiative and dynamical responses of the middle atmosphere to the 11-year solar cycle, J. Atmos. Sol.-Terr. Phy., 67, 125-143, 2005.

Sioris, C. E., McLinden, C. A., Fioletov, V. E., Adams, C., Zawodny, J. M., Bourassa, A. E., Roth, C. Z., and Degenstein, D. A.: Trend and variability in ozone in the tropical lower stratosphere over 2.5 solar cycles observed by SAGE II and OSIRIS, Atmos. Chem. Phys., 14, 3479-3496, doi:10.5194/acp-14-3479$2014,2014$.

Soukharev, B. E. and Hood, L. L.: Solar cycle variation of stratospheric ozone: Multiple regression analysis of long-term satellite data sets and comparisons with models, J. Geophys. Res., 111, D20314, doi:10.1029/2006JD007107, 2006.

Tegtmeier, S., Hegglin, M. I., Anderson, J., Bourassa, A., Brohede, S., Degenstein, D., Froidevaux, L., Fuller, R., Funke, B., Gille, J., Jones, A., Kasai, Y., Krüger, K., Kyrölä, E., Lingenfelser, G., Lumpe, J., Nardi, B., Neu, J., Pendlebury, D., Remsberg, E., Rozanov, A., Smith, L., Toohey, M., Urban, J., von Clarmann, T., Walker, K. A., and Wang, R. H. J.: SPARC Data Initiative: A comparison of ozone climatologies from international satellite limb sounders, J. Geophys. Res., 118, 12229-12247, 2013.
Thiéblemont, R., Matthes, K., Omrani, N.-E., Kodera, K., and Hansen, F.: Solar forcing synchronizes decadal North Atlantic climate variability, Nature Communications, 6, 8268, doi:10.1038/ncomms9268, 2015.

Toohey, M., Hegglin, M. I., Tegtmeier, S., Anderson, J., Anl, J. A., Bourassa, A., Brohede, S., Degenstein, D., Froidevaux, L., Fuller, R., Funke, B., Gille, J., Jones, A., Kasai, Y., Krüger, K., Kyrölä, E., Neu, J., Rozanov, A., Smith, L., Urban, J., von Clarmann, T., Walker, K. A., and Wang, R. H. J.: Characterizing sampling biases in the trace gas climatologies of the SPARC Data Initiative, J. Geophys. Res., 118, 11847-11862, 2013.

Tummon, F., Hassler, B., Harris, N. R. P., Staehelin, J., Steinbrecht, W., Anderson, J., Bodeker, G. E., Bourassa, A., Davis, S. M., Degenstein, D., Frith, S. M., Froidevaux, L., Kyrölä, E., Laine, M., Long, C., Penckwitt, A. A., Sioris, C. E., Rosenlof, K. H., Roth, C., Wang, H.-J., and Wild, J.: Intercomparison of vertically resolved merged satellite ozone data sets: interannual variability and long-term trends, Atmos. Chem. Phys., 15, 3021-3043, doi:10.5194/acp-15-3021-2015, 2015.

Wang, H. J., Cunnold, D. M., Thomason, L. W., Zawodny, J. M., and Bodeker, G. E.: Assessment of SAGE version 6.1 ozone data quality, J. Geophys. Res., 107, D234691, doi:10.1029/2002JD002418, 2002.

Wild, J. D. and Long, C. S.: A Coherent Ozone Profile Dataset from SBUV, SBUV/2: 1979 to 2013, in preparation, 2015. 